This item was submitted to Loughborough's Research Repository by the author.

Items in Figshare are protected by copyright, with all rights reserved, unless otherwise indicated.

\title{
Predicting asset returns in the BRICS: The role of macroeconomic and fundamental predictors
}

PLEASE CITE THE PUBLISHED VERSION

http://dx.doi.org/10.1016/j.iref.2015.09.001

PUBLISHER

(C) Elsevier

VERSION

AM (Accepted Manuscript)

\section{PUBLISHER STATEMENT}

This work is made available according to the conditions of the Creative Commons Attribution-NonCommercialNoDerivatives 4.0 International (CC BY-NC-ND 4.0) licence. Full details of this licence are available at: https://creativecommons.org/licenses/by-nc-nd/4.0/

\section{LICENCE}

CC BY-NC-ND 4.0

\section{REPOSITORY RECORD}

Sousa, Ricardo M., Andrew Vivian, and Mark Wohar. 2019. "Predicting Asset Returns in the BRICS: The Role of Macroeconomic and Fundamental Predictors”. figshare. https://hdl.handle.net/2134/21582. 


\title{
Predicting Asset Returns in the BRICS:
}

\section{The role of macroeconomic and fundamental predictors}

\begin{abstract}
We are among the first to provide evidence for the BRICS countries on the predictability of stock returns using macroeconomic, macro-financial and US/global variables, and find that there is predictability for all the countries. We consider both in-sample and out-of-sample tests. The gains in predictability are primarily available one quarter ahead, but in some cases two and four quarters ahead.

Keywords: Return forecasting, BRICS countries, Macro variables, Macro-financial variables, US/Global variables, Emerging markets.
\end{abstract}




\section{INTRODUCTION}

A review of the large body of work examining stock return predictability indicates that most return forecasting evidence resides in major developed countries and is especially focused on the US. This literature generally suggests that it is difficult to consistently reject the null of no predictability both in-sample (INS) and out-of-sample (OOS). For example, in their US study, Goyal and Welch (2008, p. 1504) comment that: "Despite extensive search, we were unsuccessful in identifying any models on annual or shorter frequency that systematically had both good INS and OOS performance, at least in the period from 1975 to 2005.”.

The international (non-US) literature considers several macro variables, as well as fundamental variables based on dividends and earnings (Bossaerts and Hillion, 1999; Rapach et al., 2005; Giot and Petitjean, 2011), as predictors of stock returns. This international literature has, in general, provided mixed evidence on the extent of out-ofsample (OOS) predictability. Perhaps, more importantly, it focuses primarily on developed markets especially the G-7. This raises an important issue. Major developed countries stock returns are highly correlated with each other; for example, over the sample period employed in these papers, the quarterly return correlations amongst the US-UK, USGermany and UK-Germany country pairs are all above 0.85 .

Thus far, there is relatively little international evidence from developing countries in terms of stock return predictability and, in particular, the role of macro-financial variables has not been considered in great detail for emerging markets. ${ }^{1}$ Some notable exceptions include Fifield et al. (2002), Rapach et al. (2011), Jordan et al. (2012, 2014), Gebka and Wohar (2013) and Narayan et al. (2014). For instance, Fifield et al. (2002) focus on macroeconomic indicators and financial variables to investigate stock return predictability in emerging market economies, while Rapach et al. (2011) employ similar indicators to study China. Jordan et al. (2014) investigate the role played by information emanating from trading partner countries upon the Chinese stock market return. Jordan et al. (2012) apply the bagging method to forecast stock returns for a broad set of Asian countries including

\footnotetext{
${ }^{1}$ From a macroeconomic perspective, Peltonen et al. (2012) investigate the importance of wealth effects on consumption using a panel of 14 emerging market economies. The authors show that these are reasonably large in magnitude, but typically smaller in Latin America.
} 
China and India, thereby, taking explicitly into account model uncertainty and parameter uncertainty. The authors show that bagging generally improves forecast accuracy and generates economic gains relative to the benchmark model. Gebka and Wohar (2013) argue that, despite the absence of causality between past trading volume and market returns in the Pacific Basin countries as indicated by the OLS framework, a quantile regression method is able to uncover important nonlinear causality. Mensi et al. (2014) also use a quantile regression approach and find that the BRICS stock markets are influenced by the dynamics of the global stock and commodity markets and the variation in the U.S. stock market uncertainty. ${ }^{2}$ Narayan et al. (2014) use a panel of 18 emerging markets to test for the predictive power of a wide range of institutional and macroeconomic factors for excess stock returns. The authors rely on a principal component analysis and uncover some evidence of in-sample predictability.

The main contribution of this paper is to analyze in a rigorous and detailed manner the macro-financial variables that predict BRICS country stock returns. There is, to our knowledge, little empirical evidence on the effectiveness of macro-finance variables for a dataset of emerging stock market returns. For instance, while Jordan et al. (2014) provide out-of-sample evidence of predictability for a major emerging stock market (i.e. China), their work is based on relations between trade partners. As a result, the set of predictors included in their study only covers financial indicators, namely, the stock market returns of countries from which China net imports. Similarly, Narayan et al. (2014) evaluate the role of institutions (such as, corruption, domestic conflicts, ethnic tensions and law and order) and macroeconomic indicators (budget balance, current account, debt service, exchange rate stability, foreign debt, GDP growth, inflation, net international liquidity and per capita GDP) in explaining risk premium in emerging market economies. Instead, our work focuses

\footnotetext{
${ }^{2}$ Quantile regressions have been extensively used in the empirical finance literature. For instance, Taylor (1999), Engle and Manganelli (2004) and Rubia and Sanchis-Marco (2013) make use of this technique to address value-at-risk. Conley and Galenson (1998) and Gosling et al. (2000) use quantile regressions to explore the dynamics of the distribution of asset wealth. Bassett and Chen (2001) provide a description of mutual fund strategies, Machado and Sousa (2006) investigate the role played by macroeconomic fundamentals on the distribution of stock prices, and Adrian and Brunnermeier (2011) look at the issue of systemic risk through the lens of quantile regressions. Other works making use of the same econometric framework to investigate the dependence among global stock markets and the relationship between analysts' forecast dispersion and asset returns include Leon $\mathrm{Li}$ and Yen (2011) and Leon $\mathrm{Li}$ and $\mathrm{Wu}$ (2014). Leon Li and Miu (2010) develop a bankruptcy prediction model with dynamic accounting-ratio-based and marketbased information.
} 
on several macroeconomic and macro-financial variables that are directly linked with various asset pricing models developed by the empirical finance literature. In fact, we follow closely the research that has typically looked at the predictive ability of macrofinancial empirical proxies that capture time-variation in expectations about future returns (Lettau and Ludvigson, 2001; Goyal and Welch, 2003, 2008; Della Corte et al., 2010; Sousa, 2010; Rocha Armada et al., 2015). ${ }^{3}$ Thus, we consider not only macroeconomic predictors (such as, commodity price inflation, money growth, nominal central bank rate, output gap, overall inflation, real bilateral exchange rate vis-a-vis the US Dollar and the risk-free rate), but also at macro-financial predictors (namely, the equity price scaled by GDP, the consumption-wealth ratio and the wealth-to-income ratio).

Furthermore we provide analysis of whether domestic economic variables or US/Global economic variables or both can predict aggregate stock returns in emerging markets. A recent paper by Nitschka (2014) investigates the predictive ability of the output gap for stock market returns in emerging markets, and distinguishes between the impact of national and global macroeconomic conditions. This assessment is motivated by the international macroeconomics literature on the dynamics of international business cycles and the question of knowing whether emerging markets' business cycles are aligned with developed markets' business cycles or not. Consequently, we contribute to this literature by comparing the results based on purely domestic predictors with those relying on U.S. data of all of the variables and also a selected number of global factors (including the options exchange volatility index (VIX) and the growth in international bank claims).

Summing up, our paper tries to answer the following questions:

(i) Can macro-finance variables predict stock returns in a set of emerging markets? We test if the macro-finance variables have significant predictive ability. Bootstrapped test statistics are implemented to address the persistence and possible non-normal distribution of data.

(ii) Does predictability of macro-finance variables exist out-of-sample? Prior empirical investigation of the consumption-wealth-income variable (CAY), a key macro-

\footnotetext{
${ }^{3}$ For this reason, we focus on stock return predictability instead of considering the issue of asset return volatility. For a review of this topic, see, for instance, Arouri et al. (2012) who investigate the persistence of volatility in some asset classes (such as metal commodities).
} 
finance variable, suggests that while it is effective in-sample, it is unable to improve forecast accuracy relative to the benchmark (Della Corte et al., 2010). Della Corte et al. (2010) examine four large developed markets (France, Japan, UK and US). We examine, in the context of five major emerging markets (i.e. the BRICS - Brazil, Russia, India, China and South Africa), if out-of-sample (OOS) evidence is consistent with in-sample (INS) evidence.

(iii) Do global macroeconomic conditions provide a better assessment of the risk premium dynamics in emerging market economies than domestic conditions? In this context, we repeat our in-sample and out-of-sample forecast analysis looking at the same set of macroeconomic and macro-financial indicators for the emerging markets under consideration (i.e. the domestic conditions) and the U.S. (which proxies for the international environment), as well as a group of global factors.

Our analysis focuses on the BRICS countries for various reasons. First, this economic block covers the largest emerging market economies, with very fast growth over the past decades. Second, the five emerging markets under consideration represent close to $40 \%$ of the world's population and near $20 \%$ of the world's GDP, and display an increasingly important role for equity markets in terms of financing investment opportunities and stock market capitalization. Third, their major institutional framework for monetary policy is the inflation targeting, which helps making economic decisions more predictable, with beneficial effects for domestic risk premium. Fourth, the general trend of improvement in the fiscal stance and increased discipline of public finances has contributed to the independence of the monetary authority by means of avoiding debt monetization and broadening the resident-base of domestic debt holders, as well as reducing sovereign risk spreads. Fifth, sounder macroeconomic policies and a low and stable inflation boosted the effectiveness of monetary policy and helped to anchor agents' expectations. This has, in turn, led to a strengthening of lending conditions, easier access to credit markets and a renewed confidence on domestic-currency assets, thus, reshuffling asset portfolio composition away from foreign assets.

In our study, we report both in-sample and out-of-sample predictive regression results (as do Goyal and Welch (2008) amongst many others). Traditionally, OOS tests reject the null of no predictability less frequently than INS tests. This leads to the view that 
assessments of predictability, “... must rely primarily on the out-of-sample forecasting performance...” (Ashley et al., $1980 \mathrm{p}$ 1149). The reasoning for this is that INS tests might give spurious inferences when OOS tests are not used for corroboration. In contrast, Inoue and Kilian (2005) question this interpretation; they provide evidence that INS tests have greater power than OOS tests in the setting they consider. Nevertheless, it seems plausible that instances of spurious inference are reduced when both INS and OOS tests confirm each other.

With respect to our INS results, we find that the output gap to GDP is the best predictor of stock returns for Brazil, Russia, China and South Africa. There is no evidence of predictability from CAY in any of the countries. There is almost no evidence in favor of the price-GDP ratio or the wealth-to-income ratio. Two major macro variables, inflation and money supply growth (M2), have very little predictive power. There thus appears to be less in-sample predictability in BRICS countries than is found for the US and G7 countries. With respect to out-of-sample predictability, we find, for all four countries, that the output gap to GDP variable, FX change and Central Bank (CB) rate show signs of OOS predictability for equity returns. We also show that US/global predictors generally perform very weakly and none of the variables is consistently significant across the BRICS countries.

The remainder of the paper is as follows. Section 2 briefly presents the data. Section 3 describes the different econometric methodologies. Section 4 discusses the empirical results. Section 5 concludes.

\section{DATA DESCRIPTION}

Our sample covers the five BRICS countries, i.e. Brazil (BR), Russia (RS), India (IN), China (CH) and South Africa (SA), over the period 1995Q1-2013Q2 employing quarterly data. ${ }^{4}$ Notably, there is little prior predictability evidence of market returns, especially OOS, for our sample countries. We use the first 40 quarterly observations as the

\footnotetext{
${ }^{4}$ Please note that for some variables data was not available for the full sample. For example, for some countries, wealth data was not available after 2011Q4. We use all available data in the tests and start and end dates for each series are displayed in Table 1. We use 40 observations before beginning OOS forecasts regardless of the start date.
} 
training period before beginning the OOS forecasting period from 2005Q2, which allows for a reasonably sized OOS test period.

Asset returns are computed using the Morgan Stanley Capital International (MSCI) Total Return Indices, which measure the market performance, including price performance and income from dividend payments. We use the indices that include gross dividends, i.e. approximating the maximum possible dividend reinvestment. The amount reinvested is the dividend distributed to individuals resident in the country of the company, but does not include tax credits.

We also obtain data for the following regressors:

- Macroeconomic predictors:

o Inflation (Goyal and Welch, 2008);

o Nominal central bank rate (Sousa and Sousa, 2013);

o Output gap (in percentage of GDP) (Cooper and Priestley, 2009);

o Growth rate of the monetary aggregate $\left(\mathrm{M}_{2}\right)$ (Sousa and Sousa, 2013);

o Growth rate of the commodity price index (Sousa and Sousa, 2013);

o Change in real bilateral exchange rate vis-a-vis the US Dollar (Sousa and Sousa, 2013); and

o Risk-free rate / Money market rate, i.e. the interest rate on a low risk short-term security (Goyal and Welch, 2008). ${ }^{5}$

- Macro-financial predictors:

o Consumption-wealth ratio (CAY) (Lettau and Ludvigson, 2001);

o Wealth-to-income ratio (Sousa, forthcoming); and

o Equity price scaled by GDP (Rangvid, 2006).

- Global predictors:

o US variables for the same set of determinants considered above;

o Output gap (in percentage of GDP) for the G7 countries (Cooper and Priestley, 2013; Nitschka, 2014);

o Chicago Board Options Exchange Volatility Index (VIX index); and

\footnotetext{
${ }^{5}$ For a cointegration analysis of the term structure of interest rates, see, for instance, Siklos and Wohar (1996).
} 
o Growth rate of international bank claims (i.e. growth rate of credit to non-banks and growth rate of credit to banks).

The macroeconomic predictors are obtained from Haver Analytics. As for the macro-financial predictors, the consumption-wealth ratio is computed using data for: (i) the household final consumption expenditure (in percentage of GDP) from the World Development Indicators (WDI) of the World Bank; (ii) the stock market capitalization (in percentage of GDP) from the Federal Reserve Bank of St Louis; (iii) the real GDP from Haver Analytics; and (iv) the equity price index obtained from Haver Analytics (in the case of Brazil, China, India) and the Global Financial Database (for Russia and South Africa).

Finally, the global predictors are gathered from various sources. In the case of the US variables, we obtain data for private consumption, GDP and inflation from the International Financial Statistics (IFS) of the International Monetary Fund (IMF). Asset wealth, nominal central bank rate, risk-free rate/money market rate and growth rate of the monetary aggregate $\left(\mathrm{M}_{2}\right)$ are gathered from the Board of Governors of the Federal Reserve Bank System. The commodity price index corresponds to the producer price index - all commodities, which comes from the U.S. Bureau of Labor Statistics (BLS). The nominal effective exchange rate (narrow index) is provided by the Bank for International Settlements (BIS). In what concerns the output gap (in percentage of GDP) for the G7 countries, we follow Cooper and Priestley (2013) and Nitschka (2014) and regress the natural logarithm of each of the G7 countries' industrial production indexes from the IFS of the IMF on a linear and quadratic time trend. Finally, the growth rate of international bank claims (i.e. the growth rate of credit to non-banks and the growth rate of credit to banks) is obtained from the BIS, while the Chicago Board Options Exchange Volatility Index (VIX index) is gathered from Bloomberg.

Table 1 provides a summary of descriptive statistics for our sample of BRICS countries. It reports the start date, the end date, the mean and the standard deviation for each independent variable used and for the aggregate market return. For the large majority of variables, there is data availability for the 1995Q1 to 2013Q2 sample period. However, there are some exceptions. Money supply growth is not available in Russia or China until 1998Q1. Further, we could not obtain data for any country after 2011Q4 leading to the CAY and wealth-income ratio series end dates. 
There are some notable points in relation to the mean and standard deviations of the variables. First, the average nominal returns (RET) vary substantially across countries from 0.0378 (3.78\% per quarter) in Brazil to 0.003 (0.3\% per quarter) in China. The standard deviation of returns displays wide variation across countries from 0.3275 for Russia to 0.1393 for India. The mean annualized inflation rate also varies substantially across countries with a low of 0.0309 for China to a high of 0.1471 for Brazil. Consequently the real return in all of these countries is close to zero or even negative over our sample period. For Brazil, there is high variability in a couple of macro-finance indicators (CAY and priceGDP) compared to the other countries, whereas in Russia there is relatively high variability of the risk-free proxy and central bank rate (CBRate). It could be that this high variability is connected to either fluctuating expected equity returns, which improve predictive power, or other exogenous factors, which would weaken predictive power.

\section{[INSERT TABLE 1 AROUND HERE]}

Table 2 contains the correlation matrix for returns across our sample of countries. There are considerable differences in the correlation between the different country pairs. Return correlations are highest when Brazil is one of the countries examined. For example, correlations for Brazil-Russia and Brazil-India are about 0.7. The lowest correlations are when China is one of the countries examined. The China-Russia return correlation is 0.4195 and is little more than 0.5 for China-India and China-Brazil. These relatively lower correlations for China plausibly reflect the fact that the Chinese market is more segmented than the other markets and has greater restrictions of foreign investor holdings than the other countries. Overall, while our sample country returns are positively correlated, they are substantially less correlated than quarterly market returns amongst US, UK and Germany country pairs, which are in excess of 0.85 over 1995Q1-2013Q2.

\section{[INSERT TABLE 2 AROUND HERE]}

\section{METHODOLOGY}

\subsection{In-Sample Forecast Regressions}

Individual predictive regression models are used to estimate the linkage between the dependent variable and a potential predictor variable (including its lags). Define $\Delta \mathrm{RI}_{\mathrm{t}}=\mathrm{RI}_{\mathrm{t}}$ - $R I_{t-1}$, where $R I_{t}$ is the log-level of stock return index (stock price index that includes 
reinvested dividends at time $t$ ). In addition, define $y_{t+h}^{h}=(1 / h) \sum_{j=1}^{h} \Delta R I_{t+j}$ so that $y_{t+h}^{h}$ is the (approximate) growth rate of stock returns from time $t$ to $t+h$, where $h$ is the forecast horizon. The predictive regression model takes the form of:

$$
y_{t+h}^{h}=\alpha+\lambda_{j} x_{i, t-j}+\varepsilon_{t+h}^{h}
$$

This model can be employed to estimate $h$-step ahead forecasts of stock returns using a recursive expanding window, $y_{t+h}^{h}$, which is linear in the potential predictor variables (i.e., $\mathrm{X}_{\mathrm{t}}$ ). The parameter $\alpha$ is a constant, the parameters $\lambda_{\mathrm{j}}$ capture the effect of the potential predictor variable and $\varepsilon_{t+h}^{h}$ is an error term. This is the most common model from the literature on return predictability (Goyal and Welch, 2008; Rapach Strauss and Zhou, 2010). The above equation can be estimated with ordinary least squares and this provides mean estimates of the relation between the predictive content of the explanatory variables and the dependent variable.

\subsection{Out-of-Sample Forecast Regressions}

For our out-of-sample tests, the benchmark that we use is the random walk with drift (i.e. the historical average), which is consistent with Goyal and Welch (2008) amongst many others. Clark and McCracken (2001) and McCracken (2007) develop a set of asymptotics that allow for an out-of-sample test of equal population-level predictive ability between two nested models. They show that, in the context of linear, OLS-estimated models, a number of different statistics can be employed to test for equal forecast accuracy and forecast encompassing, despite the fact that the models are nested. Based on Monte Carlo simulations, Clark and McCracken (2001, 2004) indicate that ENC-NEW is the most powerful statistic, followed by their ENC - T, MSE - F and the MSE - T statistics. These rankings suggest that the forecast encompassing statistics, especially, ENC - NEW (which is an $F$ type test and is related to the Harvey et al. (1998) statistic designed to test for forecast encompassing), can have important power advantages over test statistics based on relative MSFE.

The $E N C-N E W$ statistic is computed as

$$
E N C-N E W=(T-R-h+1) \cdot \bar{c} / M S E_{1},
$$


where $R$ is the number of observations in the in-sample period $\bar{c}=(T-R-h+1)^{-1} \sum_{t=R}^{T-h} \hat{c}_{t+h} \quad, \quad \hat{c}_{t+h}=\hat{u}_{1, t+h}\left(\hat{u}_{1, t+h}-\hat{u}_{2, t+h}\right), \quad \hat{u}_{i, t+h}=y_{t+h}-\hat{y}_{i, t+h}, i=1,2$, $M S E_{i}=(T-R-h+1)^{-1} \sum_{t=R}^{T-h} \hat{u}_{i, t+h}^{2}(i=1,2) . \quad \hat{y}_{i}$ is the forecast from model $\mathrm{i}, \mathrm{i}=1$ is the benchmark and $\mathrm{i}=2$ is the predictive model. Extensive Monte Carlo simulations in Clark and McCracken (2001, 2004) show that the ENC - NEW statistic has power advantages over the original Diebold and Mariano (1995) statistic as well as the Harvey et al. (1998) ENC - T statistic.

Under the null hypothesis, the restricted model forecasts encompass the unrestricted model forecasts, while under the one-sided (upper-tail) alternative hypothesis, is that the restricted model forecasts do not encompass the unrestricted model forecasts. Clark and McCracken (2001) note that the limiting distribution of the ENC - NEW statistic is non-standard and pivotal for one step ahead forecasts $(h=1)$ considered in this paper.

Clark and McCracken (2004) recommend basing inferences the ENC - NEW statistics on a bootstrap procedure, given that the statistics are not in general asymptotically pivotal (when $h>1$ ). The bootstrap procedure we employ is similar to the one in Clark and McCracken (2004), which is a version of the Kilian (1999) bootstrap procedure, and is discussed in detail in Rapach and Weber (2004) and Rapach and Wohar (2006).

The ENC - $t$ test of Harvey et al. (1998) is defined below:

$$
E N C-t=\frac{(T-R-h+1)^{-1 / 2} \sum_{t=R}^{T-h} \hat{c}_{t+h}}{\hat{S}_{c c}^{1 / 2}},
$$

where $\hat{S}_{c c}$ denotes the long-run variance estimates for $\hat{c}_{t+h}$ constructed with a HAC estimator such as Newey and West's (1987).

As described above, the ENC - $t$ test applies to nested forecasting models. Clark and West (2006, 2007) demonstrate that the test can be viewed as an adjusted test for equal MSE. In this framework, the null hypothesis is a random walk and the alternative hypothesis is of a predictive regression. If the null hypothesis of a random walk is true then it will have a lower mean-squared error relative to the alternative (despite the fact the alternative include an additional variable) due to the fact that there is sampling error 
associated with estimating the alternative model. Therefore, the authors adjust the forecast error of the alternative model to account for this sampling error. The adjustment subtracts the square of the difference in forecasts from the competing models; this term captures (under the null hypothesis of equal accuracy in population) the extra sampling error in the larger model. Clark and West $(2006,2007)$ present the loss differential of the test statistic as:

$$
c \hat{w}_{t+h}=\hat{u}_{1, t+h}^{2}-\left(\hat{u}_{2, t+h}^{2}-\left(\hat{y}_{1, t+h}-\hat{y}_{2, t+h}\right)^{2}\right) \text {, }
$$

and then regressing the series $\left\{c \widehat{w}_{i, t+h}\right\}_{t=R}^{T-h}$. on a constant generates the adjusted MSE (CW $t$ ), which is the $t$-statistic corresponding to a zero constant and is based on a normal distribution. The second term within the brackets of equation (4) adjusts for the upward bias in MSE predicted by estimation of parameters that are zero under the null. This $t$-test statistic proposed by Clark and West $(2006,2007)$ is equivalent to the Harvey et al. (1998) ENC- $t$ test for forecast encompassing as considered in such studies as Clark and McCracken (2001, 2005).

For tests of equal predictive ability at the population level, Monte Carlo results in Clark and McCracken (2001, 2005), Clark and West (2006, 2007), and McCracken (2007) show that critical values obtained from Monte Carlo simulations of the asymptotic distributions generally yield good size and power properties for 1-step ahead forecasts, but can yield rejection rates greater than nominal size for multi-step forecasts. Similarly, results in Clark and West (2006, 2007) indicate that comparing Clark-West (equivalent to ENC - $t$ ) test against standard normal critical values can work reasonably well but exhibit size distortions as the forecast horizon increases.

To statistically assess the performance of the models, we report results from McCracken's (2007) MSE - F test. The MSE-F statistic is a one-sided test for equal forecast accuracy. More specifically it is formulated under the null that the forecast error from the regression model is equal to or larger than (inferior to) that from the historical average regression. A rejection of the null hypothesis indicates that the regression model has superior forecast performance than the benchmark. 


$$
\begin{aligned}
M S E-F & =(T-h+1) \times\left(1+\frac{1}{1-\left[O O S R^{2}\right]}\right) \\
& =(T-h+1) \times\left(1-\frac{C S E_{H A, T}}{C S E_{z, T}}\right)
\end{aligned}
$$

$h$ measures the degree of overlap, where $h$ is equal to 1 for no overlap. CSE $E_{i}$ for $\mathrm{i}=\mathrm{HA}, \mathrm{z}$ is the cumulative squared error from the historical average (HA) and from the predictive model (z) respectively. Clark and McCracken (2005) show MSE - F have non-standard statistical distributions. Hence, critical values for $M S E$ - $F$ are produced via a bootstrap procedure following Mark (1995) and implemented in a similar manner to Rapach and Wohar (2006) and Goyal and Welch (2008). We estimate the following:

$$
\begin{aligned}
& r_{t+1}=\alpha_{t+1}+\varepsilon_{1, t+1} \\
& z_{t+1}=\delta_{t+1}+\theta_{1} z_{t}+\varepsilon_{2, t+1}
\end{aligned}
$$

Parameters are estimated using the full sample and error terms are saved to generate pseudo series for $r$ and $z$. The pseudo series for $r$ and $z$ have identical length to our sample and are formed by drawing from the time-series of residuals with replacement.

\section{EMPIRICAL ANALYSIS}

\subsection{In-sample Return Predictability}

In this section, we consider INS predictability at the 1-quarter, 2-quarter and 4quarter horizon. We explore the robustness of the US INS predictability results to data covering the BRICS countries, which have very different characteristics to the US. Statistical evidence of INS predictability is found more frequently than evidence of OOS forecast accuracy in the aggregate stock return literature and in the empirical finance literature more generally. Given these empirical results, many researchers have placed greater emphasis on OOS tests than INS tests. It has also been suggested that INS tests are more susceptible to data mining or dynamic mis-specification. In an important and influential article Inoue and Kilian (2005) provide theoretical analysis that questions these conjectures about the superiority of OOS tests. Results from Inoue and Kilian (2005) indicate that in almost all the settings that they consider, INS tests of predictability are not 
less powerful than OOS tests of forecast accuracy. ${ }^{6}$ The implications for our study are as follows: first, in general, the INS two-sided $t$-tests should be at least as reliable as the OOS forecast accuracy tests. Consequently, both tests should provide similar results. Secondly, it is possible for either the INS test or the OOS test to falsely reject the null hypothesis (or falsely not reject the null hypothesis). Thus, it is useful to implement both tests to corroborate if the general results are robust. Consequently, we emphasize results that are generally found whichever test is considered.

Panel A of Table 3 presents evidence for Brazil on whether INS predictability exists suing domestic predictors and the explanatory power of each domestic country predictor variable, while Table 3, Panel B presents evidence on whether INS predictability exists and the explanatory power of each US/Global predictor variable. Tables 4-7 present corresponding evidence for Russia, India, China and South Africa. The INS predictability tests consist of regressions of one, two and four quarter ahead stock returns on current predictor variables. There are several important themes to the evidence in Table 3 . Considering first, Table 3, Panel A, using inference based on Newey-West $t$-statistics, there is evidence of predictability for at least half the variables, 5 out of 10 at the one-quarter horizon and 7 at both the two-quarter and the four-quarter horizons. Second, evidence of predictability from inference based upon bootstrapped $t$-statistics is weaker; here, it is apparent at best for half of the variables: 3 out of 10 at the one-quarter horizon, 4 at the two-quarter horizon, and 5 at the four-quarter horizon. Third, only the output gap to GDP ratio exhibits consistent predictability at all horizons for both conventional and bootstrapped inference. However, if we just consider conventional inference, there is evidence for all horizons from the foreign exchange rate, money market rate (MMR) and price-GDP. Fourth, there is virtually no evidence of predictability from CAY or the wealthto-income ratio in Brazil. Finally, there is reasonable predictive power from the output gap to GDP ratio, foreign exchange rate and price to GDP ratio; the R-squared is above $5 \%$ for all these variables at the one-quarter horizon. Overall, output gap to GDP is the strongest predictor in-sample.

\footnotetext{
${ }^{6}$ The conclusion of Inoue and Kilian (2005) is stronger, i.e., INS is typically more powerful than OOS, because they emphasize their INS one-sided t-test results. However, we implement their two-sided tests, for which INS and OOS are more comparable. Their results are robust to the data mining adjustment that they consider and the forms of dynamic mis-specification which they consider.
} 
Turning next to Table 3, Panel B, we look at US/Global predictors for Brazil stock returns and find that, using inference based on Newey-West $t$-statistics, there is evidence of predictability for at least three variables: the US output Gap variable and the price-GDP variable at the one, two, and four quarterly horizons, and the commodity price growth variable at the two-quarter horizon. Evidence of predictability from inference based upon bootstrapped $t$-statistics is weaker; here, it is apparent for only the price-GDP variable, which shows predictability at the one, two, and four-quarter horizons.

Table 4, Panel A, presents results from INS predictive regressions for Russia using domestic predictors. First, there is less evidence in favor of predictability for Russia than for Brazil. Using inference based on Newey-West t-statistics, only very few variables seem to forecast stock returns at the one quarter-ahead and two quarter-ahead horizons. Only the output gap to GDP ratio and the foreign exchange rate are significant. Second, evidence of predictability from inference based upon bootstrapped $t$-statistics is very consistent with that from conventional critical values. Third, both the output gap to GDP ratio and foreign exchange rate exhibit consistent predictability at all horizons for both conventional and bootstrapped inference. Fourth, there is no evidence of predictability from CAY, price-GDP ratio, MMR or M2 growth in Russia. Finally, there is reasonable predictive power from the output gap to GDP ratio and the foreign exchange rate; the R-squared is above $5 \%$ for these variables at the one-quarter horizon; and the R-squared for output gap to GDP is above $20 \%$ at two quarters-ahead and above $30 \%$ at four quarters-ahead. Overall, for Russia as for Brazil, we can conclude that the output gap to GDP is the strongest predictor in-sample.

Turning now to Table 4, Panel B, we look at US/Global predictors and find that the inference based on Newey-West $t$-statistics suggests that there is evidence of predictability for at least two variables: the foreign exchange (FX) rate at the one-quarter horizon and the US output gap variable at the two and four-quarter horizons. Evidence of predictability from inference based upon bootstrapped $t$-statistics is weaker, as only the FX change variable shows predictability at the one-quarter horizon.

Table 5, Panel A, presents results from INS predictive regressions for India using domestic predictors. First, there is little evidence in favour of predictability for India: 8 out of 10 variables have no evidence of predictability at any of the horizons we consider. Second, using inference based on bootstrapped $t$-statistics, this evidence is confined to one- 
quarter ahead for commodity index growth and no more than two quarters ahead for CB rate. Third, for one-quarter ahead both commodity index growth and CB rate have reasonable predictive power: the R-squared is above 5\% for both these variables. Overall, while CB rate demonstrates more statistical evidence for predictability in India, however, commodity index growth provides higher goodness of fit (R-squared).

Turning next to Table 5, Panel B, we look at US/Global predictors and find that, using inference based on Newey-West $t$-statistics, there is evidence of predictability for at least two variables: the US output gap at the one and four-quarter horizons, and commodity index growth at the two and four-quarter horizons. Evidence of predictability from inference based upon bootstrapped $t$-statistics is weaker: only the commodity index growth is significant at the two and four-quarter horizons.

Table 6, Panel A, summarizes results from INS predictive regressions for China using domestic predictors. First, similar to India, there is little evidence in favor of predictability for 4 out of 10 variables at any of the horizons under consideration. Second, of the 4 variables that display some predictability, only the output gap to GDP and the wealth-income ratio exhibit predictability using bootstrapped inference. Third, only the output gap to GDP ratio has consistent predictive power across all horizons. Fourth, the output gap to GDP has the best fit (highest r-squared) at all horizons. In short, the output gap to GDP is by far the best predictor of Chinese stock returns out of the ten variables examined.

Turning now to Table 6, Panel B, we look at US/Global predictors for China and find that, using inference based on Newey-West $t$-statistics, there is evidence of predictability for at least one variable: the US output gap variable and the price-GDP ratio at the one, two, and four-quarter horizons. Evidence of predictability from inference based upon bootstrapped $t$-statistics is weaker, as only the price-GDP variable has predictability at the one, two, and four-quarter horizons.

In Table 7, Panel A we report the empirical findings associated with the INS predictive regressions for South Africa using domestic predictors. Three variables show predictability using the Newey-West $t$-statistics: the inflation rate and the output gap at the one, two and four-quarter horizons, the risk-free rate and CBrate at the one-quarter horizon, and the growth rate of M2 at the two and four-quarter horizons. Of these variables that have 
some evidence of predictability, only inflation, output gap, real interest rate, and CB rate display predictability using bootstrapped inference. Similarly, only the output gap has consistent predictive power across all horizons. Fourth, the output gap to GDP has the best fit (i.e. highest R-squared) at all horizons. In short, the output gap to GDP is also by far the best predictor of South African stock returns.

Turning next to Table 7, Panel B, we look at US/Global predictors and find that regardless of whether we use inference based on Newey-West $t$-statistics or bootstrapped $t$ statistics, no US predictor variable is able to forecast South African stock returns.

\section{[INSERT TABLES 3-7 AROUND HERE]}

In summary, our in-sample results suggest that the output gap to GDP is the best predictor of stock returns for Brazil, Russia and China. In contrast, some of the macrofinance variables perform dismally in the large emerging markets that we consider. For example, there is no evidence of predictability from CAY (Lettau and Ludvigson, 2001) in any of the countries. Further, there is sparse evidence in favour of the price-GDP ratio (Rangvid, 2006) and wealth-to-income ratio (Sousa, forthcoming) for BRICS countries. Macro variables also generally only have limited predictive power. Interestingly, two major macro variables (i.e. inflation and money supply growth) have very little predictive power. Overall, our empirical evidence suggests there is less return predictability in BRICS countries than in the US or amongst the G7 countries. With respect to the use of US/Global predictors, the two variables that have shown signs of predictability are the output gap to GDP ratio and the price-GDP ratio. Thus, US/Global variables are found to be much poorer predictors relative to domestic predictive variables.

\subsection{Out-of-Sample Return Predictability}

Could investors' actually use fundamental-price based models in order to benefit from more accurate predictions of future stock returns? This issue is of importance to both practitioners and academics alike. Asset managers, economic policymakers, as well as pension providers and contributors all need accurate estimates of future market returns. In this section, we examine a range of fundamental-price ratios, as well as macro-finance and macro variables, for a sample of BRICS countries. We consider if individual predictors can improve forecast accuracy over the historical average benchmark model. We note that some 
of the macro-finance variables (CAY, output gap to GDP and wealth-income ratio) potentially have a look-ahead bias given they are initially estimated using full-sample values. To examine the effect of this, we also report results for versions of these variables which are calculated using information available in real-time; these variables are denoted with an "RT" suffix, for example CAY_RT. Tables 8-12 report 1, 2, and 4-quarter ahead forecast results from individual predictive regression models for Brazil, Russia, India, China and South Africa, respectively.

Table 8, Panel A, provides results for Brazil using domestic predictors. Overall, the individual predictive models have mixed results. For Brazil, in terms of the metrics (MSEF, ENC-NEW and CW-T statistics), the output gap to GDP and the output gap to GDP_RT show OOS predictive ability at 1, 2 and 4-quarter horizons; while the magnitude of the forecast gains are smaller using the real-time version of the output gap to GDP, they are still of substantial magnitude. The risk-free rate shows clear OOS predictive ability at the 1 and 4-quarter horizons. Commodity index growth has OOS predictability only at the 1quarter horizon, while the FX change has OOS predictability at the 1 and 2-quarter horizons.

Table 8, Panels B-C, provides results for Brazil using US/Global predictors. Overall, the individual predictive models have limited predictability. For Brazil, the priceGDP variable shows OOS predictive ability at 1, 2 and 4-quarter horizons, while inflation displays some OOS predictive ability at the 1 and 2-quarter horizons.

With respect to Russia (Table 9, Panel A), overall, the statistical evidence in favor of OOS predictive ability using domestic predictors is very weak. For example, only the output-gap to GDP ratio shows OOS predictability at all horizons. The output gap GDP-RT displays some OOS predictability at the 1 and 2-quarter horizons according to the ENCNEW metric, which tests for encompassing; however, the Theil's $U$ is greater than 1 , which indicates that the forecast accuracy is weaker than the benchmark. Interestingly, in terms of forecast accuracy the CB rate beats the benchmark at all horizons, but none of the statistical tests are significant for the CB rate. Overall, the evidence of OOS return predictability in Russia is not widespread.

Table 9, Panels B-C, provides results for Russia using domestic predictors, which show that only the US output gap has strong OOS predictive ability at all horizons. 
Table 10, Panel A, summarizes the findings for India using domestic predictors. Overall, the individual predictive models have mixed results. For Brazil, in terms of the metrics (MSE-F, ENC-NEW and CW-T statistics), the output gap to GDP and output gap to GDP_RT show OOS predictive ability at all horizons. The risk-free rate also shows clear OOS predictive ability at the 1 and 4-quarter horizons. Commodity index growth has OOS predictability only at the 1-quarter horizon and FX change has OOS predictability at the 1 and 2-quarter horizons.

Table 10, Panels B-C, provides evidence of predictability for a couple of US/Global variables regarding future Indian stock returns. The US commodity price growth has OOS predictability at the 2 and 4-quarter horizons, the US output gap displays OOS predictability at all horizons, and the price-GDP variable has a significant Theil's-U statistic for the 1, 2, and 4-quarter forecasting horizons.

In the case of China (Table 11, Panel A), the output gap to GDP variable has strong OOS predictability at all horizons. However, this forecasting ability largely evaporates when this predictor is formed using only data available in real-time; indeed, the output gap to GDP_RT underperforms the historical average benchmark at all horizons, although its forecast is not encompassed according to the ENC-NEW test. The wealth-income ratio has some OOS predictability at the 1 and 4-quarter horizons (according to the ENC-NEW metric), although this also disappears for the real-time version of the variable (i.e. wealthincome_RT). The CB rate shows OOS predictability in both the upper and lower panels at the 1, 2 and 4 quarterly horizons (according to the MSE-F and CW-t metrics). In the case of China (Table 11, Panels B-C), using US predictors, the price-GDP variable has strong OOS predictability at all horizons.

For South Africa (Table 12, Panel A), using domestic predictors, both the inflation rate and the output gap have strong OOS predictability at the 1, 2 and 4-quarter horizons. The risk-free rate and the $\mathrm{CB}$ rate have predictive ability OOS at the 1 and 2-quarter horizons. With respect to the use of US predictors (Table 12, Panels B-C), we find very little evidence of OOS predictability. The price-GDP variable has a significant Theil's-U statistic at the 1 and 4-quarter horizons, while CAY has a significant ENC-NEW statistic at the 2-quarter horizon.

[INSERT TABLE 8-12 AROUND HERE] 
We also provide some robustness analysis by including a lagged dependent variable as one of the predictors. Our results (in Appendix A) show that results are qualitatively the same as to those without a lagged dependent variable as a predictor. This should not be surprising as aggregate stock returns tend not to be highly serially correlated at a quarterly frequency.

In summary, we conduct an extensive analysis of OOS return predictability for the five BRICS countries. Overall, we find very little evidence of predictability in the emerging markets using the macro-finance variables (CAY, wealth-income and price-GDP) that have been advocated in studies of developed markets. However, the output gap to GDP variable, the $\mathrm{CB}$ rate and the change in FX show signs of OOS predictability for equity returns. Thus, there is some evidence of OOS return predictability from macro variables for the large emerging countries under investigation. The two US predictors that show OOS predictive ability are the output gap to GDP ratio and the price-GDP ratio.

\section{CONCLUSION}

A huge amount of research investigates the link between the macroeconomy and financial markets. Despite this, there are several issues that have not yet been adequately addressed, especially given that empirical evidence focuses on developed markets. One of these issues is whether expected future stock returns can be accurately predicted by macroeconomic or macro-financial indicators. This study provides novel evidence on this issue by examining large emerging market economies for which there is relatively little evidence in this context. ${ }^{7}$

We examine several predictors, most of which have been found to have INS predictive power in the US . In contrast, there is very little evidence for the variables from emerging markets. We provide a first step in this direction by studying a sample of five large emerging markets, i.e. the BRICS nations. This lack of literature is surprising given that they are the world's most populous countries and are growing in importance economically. In our tests, we consider macroeconomic, macro-financial and US/global variables. To our knowledge, we are the first to undertake such a broad analysis of the

\footnotetext{
${ }^{7}$ Notable exceptions are Narayanan et al. (2014) and Jordan et al. (2014), for China.
} 
BRICS countries, which are vitally important emerging markets and growing economic powerhouses.

We provide evidence on the questions: (i) Can domestic macro-finance variables predict stock returns in a set of emerging markets? (ii) Do US/global macro-finance variables predict emerging market stock returns? (iii) Does predictability of macro-finance variables exist out-of-sample?

Firstly, we test if the macro-finance variables have significant predictive ability. We find that the output gap to GDP ratio is the best predictor for Brazil, Russia and China. However, other macro variables (such as, inflation and interest rates) and macro-finance variables (such as CAY) have little predictive power for the BRICS countries over the sample period of 1995Q1-2013Q2.

Secondly, we examine if US/global macro-finance variables have predictive ability for emerging market economies. We find that they are generally even weaker predictors of BRICS stock returns than their domestic counterparts.

Thirdly, prior empirical investigation suggests that in-sample predictability does not guarantee an ability to forecast out-of-sample relative to the benchmark model (Della Corte et al., 2010). Thus, we investigate for five major emerging markets if out-of-sample evidence is consistent with in-sample evidence. Our results show that there is more evidence of predictability from OOS tests than from INS tests. We find that the evidence from standard forecast accuracy metrics (e.g., mean-squared forecast error) is actually more favorable to predictability than results from simple regressions.

In summary, the empirical evidence of return predictability for BRICS countries is somewhat limited over the 2005-2013 OOS period. Prior empirical investigations of return predictability in the US and G7 countries tends to uncover more significant findings. The results from this paper suggest that it is important to examine if variables proposed based on US data actually have consistent forecast power globally; our evidence from emerging markets suggest that they may not. 


\section{BIBLIOGRAPHY}

Adrian, T., Brunnermeier, M.K., 2011. CoVaR. National Bureau of Economic Research, NBER, Working Paper No. 17454.

Ashley, R., Granger, C.W.J., Schmalensee, R., 1980. Advertising and aggregate consumption: An analysis of causality. Econometrica, 48, 1149-1167.

Arouri, M.E.H., Hammoudeh, S., Lahiani, A., Nguyen, D.K., 2012. Long memory and structural breaks in modeling the return and volatility dynamics of precious metals. Quarterly Review of Economics and Finance, 52(2), 207-218.

Bassett, G., H.-L. Chen, 2001. Quantile style: Return-based attribution using regression quantiles. Empirical Economics, 26(1), 293-305.

Bossaerts, P., Hillion, P., 1999. Implementing statistical criteria to select return forecasting models: What do we learn? Review of Financial Studies, 12(2), 405-428.

Clark T.E., McCracken, M.W., 2001. Tests of equal forecast accuracy and encompassing for nested models. Journal of Econometrics, 105(1), 85-110.

Clark, T.E., McCracken, M.W., 2004. Evaluating long-horizon forecasts. University of Missouri - Columbia, Manuscript.

Clark, T.E., McCracken, M.W., 2005. Evaluating direct multistep forecasts. Econometric Reviews, 24, 369-404.

Clark, T.E., West, K.D., 2006. Using out-of-sample mean squared prediction errors to test the martingale difference hypothesis. Journal of Econometrics, 135, 155-186.

Clark, T.E., West, K.D., 2007. Approximately Normal tests for equal predictive accuracy in nested models. Journal of Econometrics, 138, 291-311.

Conley, T., Galenson, D., 1998. Nativity and wealth in mid-nineteenth-century cities. Journal of Economic History, 58(2), 468-493.

Cooper, I., Priestley, R., 2009. Time-varying risk premiums and the output gap. Review of Financial Studies, 22(7), 2801-2833.

Cooper, I., Priestley, R., 2013. The world business cycle and expected stock returns. Review of Finance, 17, 1029-1064.

Della Corte P., Sarno, L., Valente, G., 2010. A century of equity premium predictability and the consumption-wealth ratio: An international perspective. Journal of Empirical Finance, 17(3), 313-331. 
Diebold, F.X., Mariano, R.S., 1995. Comparing predictive accuracy. Journal of Business and Economic Statistics, 13, 253-263.

Engle, R.F., Manganelli, S., 2004. CAViaR: conditional autoregressive value at risk by regression quantiles. Journal of Business and Economic Statistics, 22, 367-381.

Fifield, S.G.M., Power, D.M., Sinclair, C.D., 2002. Macroeconomic factors and share returns: An analysis using emerging market data. International Journal of Finance and Economics, 7, 51-62.

Gebka, B., Wohar, M.E., 2013. Causality between trading volume and returns: Evidence from quantile regressions. International Review of Economics and Finance, 27(C), 144159.

Giot, P., Petitjean, M., 2011. On the statistical and economic performance of stock return predictive regression models: an international perspective. Quantitative Finance, 11(2), 175-193.

Gosling, A., Machin, S., Meghir, C., 2000. The changing distribution of male wages in the U.K.. Review of Economic Studies, 67(4), 635-666.

Goyal, A., Welch, I., 2003. Predicting the equity premium with dividend ratios. Management Science, 49(5), 639-654.

Goyal, A., Welch, I., 2008. A comprehensive look at the empirical performance of the equity premium prediction. Review of Financial Studies, 21(4), 1455-1508.

Harvey, D.I., Leybourne, S.J., Newbold, P., 1998. Tests for forecast encompassing. Journal of Business and Economic Statistics, 16(2), 254-259.

Inoue, A., Kilian, L., 2005. In-sample or out-of-sample tests of predictability: Which one should we use? Econometric Reviews, 23(4), 371-402.

Jordan, S.J., Vivian, A.J., Wohar, M.E., 2012. Forecasting Asian market returns: Bagging or combining? Loughborough University, manuscript.

Jordan, S.J., Vivian, A.J., Wohar, M.E., 2014. Sticky prices or economically-linked economies: The case of forecasting the Chinese stock market. Journal of International Money and Finance, 41, 95-109.

Kilian, L., 1999. Exchange rates and monetary fundamentals: What do we learn from longhorizon regressions? Journal of Applied Econometrics, 14(5), 491-510. 
Leon Li, M.-Y., Miu, P., 2010. A hybrid bankruptcy prediction model with dynamic loadings on accounting-ratio-based and market-based information: A binary quantile regression approach. Journal of Empirical Finance, 17, 818-833.

Leon Li, M.-Y., Wu, J.S., 2014. Analysts' forecast dispersion and stock returns: A quantile regression approach. Journal of Behavioral Finance, 15(3), 175-183.

Leon Li, M.-Y., Yen, M.-F., 2011. Reexamining dynamic covariance risk in global stock markets using quantile regression analysis. Acta Oeconomica, 61, 33-59.

Lettau, M., Ludvigson, S., 2001. Consumption, aggregate wealth, and expected stock returns. Journal of Finance, 56, 815-849.

Machado, J.A.F., Sousa, J., 2006. Identifying asset price booms and busts with quantile regressions. Banco de Portugal, Working Paper No. 8.

Mark, N.C., 1995. Exchange rates and fundamentals: Evidence on long-horizon predictability. American Economic Review, 85, 201-218.

McCracken, M.W., 2007. Asymptoptics for out-of-sample tests of Granger causality. Journal of Econometrics, 140(2), 719-752.

Mensi, W., Hammoudeh, S., Reboredo, J.C., Nguyen, D.K., 2014. Do global factors impact BRICSS stock markets? A quantile regression approach. Emerging Markets Review, 117.

Narayan, P.K., Narayan, S., Thuraisamy, K.S., 2014. Can institutions and macroeconomic factors predict stock returns in emerging markets? Emerging Markets Review, 19, 77-95.

Newey, W.K., West, K.D., 1987. A simple positive semi-definite heteroskedasticity and autocorrelation consistent covariance matrix. Econometrica, 55(3), 703-708.

Nitschka, T., 2014. Developed markets' business cycle dynamics and time-variation in emerging markets' asset returns. Journal of Banking \& Finance, 42, 76-82.

Peltonen, T.A., Sousa, R.M., Vansteenkiste, I.S., 2012. Wealth effects in emerging market economies. International Review of Economics and Finance, 24, 155-166.

Rangvid, J., 2006. Output and expected returns. Journal of Financial Economics, 81, 594624.

Rapach, D.E., Jiang, F., Tu, J., Zhou, G.F., 2011. How predictable is the Chinese market. Journal of Financial Research (in Chinese), 9, 107-121. 
Rapach, D.E., Strauss, J.K., Zhou, G.F., (2010. ), “Out-of-sample equity premium prediction: Combination forecasts and links to the real economy. ”, Review of Financial Studies, 23(2), 821-862.

Rapach, D.E., Weber, C.E., 2004. Financial variables and the simulated out-of-sample forecastability of U.S. output growth since 1985: An encompassing approach. Economic Inquiry, 42, 717-738.

Rapach, D.E., Wohar, M.E., 2006. In-sample vs. out-of-sample tests of stock return predictability in the context of data mining. Journal of Empirical Finance, 13, 231-247.

Rapach, D.E., Wohar, M.E., Rangvid, J., 2005. Macro variables and international stock return predictability. International Journal of Forecasting, 21(1), 137-166.

Rocha Armada, M.J., Sousa, R.M., Wohar, M.E., 2015. Consumption growth, preference for smoothing, changes in expectations and risk premium. Quarterly Review of Economics and Finance, 56, 80-97.

Rubia, A., Sanchis-Marco, L., 2013. On downside risk predictability through liquidity and trading activity: a dynamic quantile approach. International Journal of Forecasting, 29, 202-219.

Siklos, P.L., Wohar, M.E., 1996. Cointegration and term structure: A multicountry comparison. International Review of Economics and Finance, 5(1), 21-34.

Sousa, R.M., 2010. Consumption, (dis)aggregate wealth, and asset returns. Journal of Empirical Finance, 17(4), 606-622.

Sousa, R.M., forthcoming. Linking wealth and labour income with stock returns and government bond yields. European Journal of Finance.

Sousa, J., Sousa, R.M., 2013. Asset returns under model uncertainty: Evidence from the euro area, the U.K. and the U.S. European Central Bank, ECB Working Paper No. 1575.

Taylor, J., 1999. A quantile regression approach to estimating the distribution of multiperiod returns. Journal of Derivatives, 7(1), 64-78. 
Table 1: Sample period, mean and standard deviation of asset returns and predictors.

\begin{tabular}{|c|c|c|c|c|c|c|c|c|c|c|c|c|c|c|c|c|c|c|c|c|}
\hline & \multicolumn{4}{|c|}{ Brazil } & \multicolumn{4}{|c|}{ Russia } & \multicolumn{4}{|c|}{ India } & \multicolumn{4}{|c|}{ China } & \multicolumn{4}{|c|}{ South Africa } \\
\hline & Start & End & Mean & SD & Start & End & Mean & SD & Start & End & Mean & SD & Start & End & Mean & SD & Start & End & Mean & SD \\
\hline Returns & 1995Q1 & 2013Q2 & 0.0378 & 0.1493 & 1995Q1 & 2013Q2 & 0.0307 & 0.3275 & 1995Q1 & 2013Q2 & 0.0262 & 0.1393 & 1995Q1 & 2013Q2 & 0.0030 & 0.1776 & 1995Q1 & 2013Q2 & 0.0306 & 0.0939 \\
\hline Inflation-Inf & 1995Q1 & 2013Q2 & 0.1471 & 0.5249 & 1995Q1 & 2013Q2 & 0.3009 & 0.4832 & 1995Q1 & 2013Q2 & 0.0735 & 0.0344 & 1995Q1 & 2013Q2 & 0.0309 & 0.0445 & 1995Q1 & 2013Q2 & 0.0627 & 0.0278 \\
\hline OutputGaptoGDP & 1996Q2 & 2013Q2 & 0.0008 & 0.0155 & 1995Q1 & 2013Q2 & 0.0015 & 0.0289 & 1996Q2 & 2013Q2 & 0.0005 & 0.0245 & 1995Q1 & 2011Q4 & 0.0015 & 0.0108 & 1995Q1 & 2013Q2 & 0.0007 & 0.0122 \\
\hline $\begin{array}{l}\text { M2Growth } \\
\text { CommodityIndex }\end{array}$ & 1995Q1 & 2013Q2 & 0.2157 & 0.4631 & 1998Q1 & 2013Q2 & 0.3379 & 0.1873 & 1995Q1 & 2013Q2 & 0.1685 & 0.0271 & 1998Q1 & 2013Q2 & 0.1697 & 0.0350 & 1995Q1 & 2013Q2 & 0.1296 & 0.0597 \\
\hline Growth & 1995Q1 & 2013Q2 & 0.0885 & 0.2063 & 1995Q1 & 2013Q2 & 0.0885 & 0.2063 & 1995Q1 & 2013Q2 & 0.0885 & 0.2063 & 1995Q1 & 2013Q2 & 0.0885 & 0.2063 & 1995Q1 & 2013Q2 & 0.0885 & 0.2063 \\
\hline FXchange & 1995Q1 & 2013Q2 & 0.0411 & 0.1782 & 1995Q1 & 2013Q2 & 0.0625 & 0.1793 & 1995Q1 & 2013Q2 & 0.0058 & 0.0804 & 1995Q1 & 2013Q2 & 0.0188 & 0.0524 & 1995Q1 & 2013Q2 & -0.0430 & 0.1326 \\
\hline CAY & 1996Q2 & 2009Q4 & 0.0184 & 0.6794 & 1995Q1 & 2011Q4 & 0.0130 & 0.0618 & 1996Q2 & 2011Q4 & 0.4054 & 0.0961 & 1995Q1 & 2011Q4 & 0.0308 & 0.1095 & 1995Q1 & 2011Q4 & 0.0389 & 0.0187 \\
\hline Wealth-Income & 1996Q2 & 2011Q4 & 0.2604 & 0.2700 & 1995Q1 & 2011Q4 & 0.5243 & 0.6691 & 1996Q2 & 2011Q4 & 0.1820 & 0.2791 & 1995Q1 & 2011Q4 & 2.5167 & 0.4932 & 1995Q1 & 2011Q4 & 0.0718 & 0.1185 \\
\hline RiskFree-MMR/TBL & 1996Q3 & 2013Q2 & 0.0484 & 0.0275 & 1995Q1 & 2013Q2 & 0.0535 & 0.1379 & 1996Q3 & 2013Q2 & 0.0213 & 0.0114 & 1995Q1 & 2013Q2 & 0.0073 & 0.0061 & 1995Q1 & 2013Q2 & 0.0992 & 0.0360 \\
\hline Price-GDP & 1995Q1 & 2013Q2 & 5.1726 & 0.7343 & 1995Q4 & 2013Q2 & 4.3389 & 0.2509 & 1995Q1 & 2013Q2 & 5.8837 & 0.4403 & 1995Q1 & 2012Q1 & 4.3752 & 0.4304 & 1995Q1 & 2013Q2 & -5.2085 & 0.4972 \\
\hline CBRate & 1995Q1 & 2013Q2 & 0.1460 & 0.0716 & 1995Q1 & 2013Q2 & 0.3277 & 0.4262 & 1995Q1 & 2013Q2 & 0.0732 & 0.0225 & 1995Q1 & 2013Q2 & 0.0674 & 0.0190 & 1995Q1 & 2013Q2 & 0.1070 & 0.0419 \\
\hline
\end{tabular}

Table 2: Return correlation matrix.

\begin{tabular}{|c|c|c|c|c|c|}
\hline Return Correlations & Brazil & Russia & India & China & South Africa \\
\hline Brazil & 1.0000 & & & & \\
\hline Russia & 0.7217 & 1.0000 & & & \\
\hline India & 0.6865 & 0.4739 & 1.0000 & & \\
\hline China & 0.5472 & 0.4195 & 0.5062 & 1.0000 & \\
\hline South Africa & 0.7299 & 0.6313 & 0.5349 & 0.4896 & 1.0000 \\
\hline
\end{tabular}


Table 3: In-sample forecast regressions - Brazil.

Panel A: Domestic Predictors

\begin{tabular}{|c|c|c|c|c|c|c|c|c|c|c|c|c|c|c|c|}
\hline \multirow[t]{2}{*}{ 1995Q1-2013Q2 } & \multicolumn{4}{|c|}{ One quarter ahead } & \multicolumn{5}{|c|}{ Two quarters ahead } & \multicolumn{6}{|c|}{ Four quarters ahead } \\
\hline & Horizon & Slope & $\mathrm{t}$ & $p(t)$ & R-sq & Horizon & Slope & $\mathrm{t}$ & $p(t)$ & R-sq & Horizon & Slope & $\mathrm{t}$ & $p(t)$ & R-sq \\
\hline Inflation-Inf & 1 & 0.1299 & 1.1551 & 0.1310 & 0.0184 & 2 & 0.2239 & 5.4656 & 0.0000 & 0.0245 & 4 & 0.2374 & 3.0823 & 0.0110 & 0.0152 \\
\hline OutputGaptoGDP & 1 & -0.2752 & -2.5299 & 0.9970 & 0.0827 & 2 & -0.5061 & -2.3001 & 0.9680 & 0.1240 & 4 & -0.7869 & -2.7330 & 0.9810 & 0.1626 \\
\hline M2Growth & 1 & 0.0706 & 0.6229 & 0.2980 & 0.0054 & 2 & 0.1572 & 2.3006 & 0.0360 & 0.0121 & 4 & 0.1717 & 2.2528 & 0.0420 & 0.0079 \\
\hline CommodityIndexGrowth & 1 & -0.1892 & -1.6958 & 0.9420 & 0.0389 & 2 & -0.3132 & -1.2147 & 0.8240 & 0.0474 & 4 & -0.3885 & -1.2039 & 0.7740 & 0.0399 \\
\hline FXchange & 1 & -0.2600 & -2.3798 & 0.9940 & 0.0739 & 2 & -0.4504 & -3.1409 & 0.9930 & 0.0990 & 4 & -0.5738 & -2.3147 & 0.9340 & 0.0881 \\
\hline CAY & 1 & 0.1353 & 1.0086 & 0.1520 & 0.0175 & 2 & 0.1629 & 0.9089 & 0.1970 & 0.0111 & 4 & -0.2248 & -0.6833 & 0.6700 & 0.0118 \\
\hline Wealth-Income & 1 & 0.1629 & 1.2900 & 0.0840 & 0.0250 & 2 & 0.3346 & 1.7897 & 0.0830 & 0.0418 & 4 & 0.1443 & 0.3840 & 0.3570 & 0.0033 \\
\hline RiskFree-MMR/TBL & 1 & 0.2036 & 1.8199 & 0.0300 & 0.0446 & 2 & 0.3120 & 1.6754 & 0.1040 & 0.0460 & 4 & 0.6763 & 2.7646 & 0.0350 & 0.1151 \\
\hline Price-GDP & 1 & -0.2321 & -2.1008 & 0.9160 & 0.0585 & 2 & -0.4570 & -2.6319 & 0.9190 & 0.1002 & 4 & -0.8161 & -3.6472 & 0.9280 & 0.1713 \\
\hline CBRate & 1 & 0.0721 & 0.5948 & 0.2590 & 0.0054 & 2 & 0.1879 & 0.8626 & 0.1980 & 0.0160 & 4 & 0.9307 & 3.6775 & 0.0170 & 0.2187 \\
\hline
\end{tabular}

Panel B: US and Global Predictors

\begin{tabular}{|c|c|c|c|c|c|c|c|c|c|c|c|c|c|c|c|}
\hline \multirow[t]{2}{*}{ 1995Q1-2013Q2 } & \multicolumn{4}{|c|}{ One quarter ahead } & \multirow[b]{2}{*}{ R-sq } & \multicolumn{4}{|c|}{ Two quarters ahead } & \multicolumn{6}{|c|}{ Four quarters ahead } \\
\hline & Horizon & Slope & $\mathrm{t}$ & $p(t)$ & & Horizon & Slope & $\mathrm{t}$ & $\mathrm{p}(\mathrm{t})$ & R-sq & Horizon & Slope & $\mathrm{t}$ & $\mathrm{p}(\mathrm{t})$ & R-sq \\
\hline Inflation-Inf & 1 & 0.1459 & 1.2257 & 0.1260 & 0.0207 & 2 & 0.2792 & 1.1313 & 0.1930 & 0.0384 & 4 & 0.4089 & 1.1872 & 0.2130 & 0.0378 \\
\hline OutputGaptoGDP & 1 & -0.2036 & -1.7255 & 0.9390 & 0.0408 & 2 & -0.3580 & -1.6815 & 0.8760 & 0.0635 & 4 & -0.6448 & -1.9431 & 0.8860 & 0.0931 \\
\hline M2Growth & 1 & -0.0029 & -0.0241 & 0.4920 & 0.0000 & 2 & 0.0716 & 0.3979 & 0.3820 & 0.0026 & 4 & 0.0033 & 0.0126 & 0.5230 & 0.0000 \\
\hline CommodityIndexGrowth & 1 & -0.1037 & -0.8791 & 0.8100 & 0.0108 & 2 & -0.3314 & -2.1622 & 0.9370 & 0.0559 & 4 & -0.2348 & -0.9148 & 0.7420 & 0.0129 \\
\hline FXchange & 1 & -0.0058 & -0.0487 & 0.5580 & 0.0000 & 2 & -0.0543 & -0.3218 & 0.6210 & 0.0015 & 4 & -0.0431 & -0.1267 & 0.5940 & 0.0004 \\
\hline CAY & 1 & 0.1247 & 1.0372 & 0.2660 & 0.0151 & 2 & 0.2478 & 1.0867 & 0.3020 & 0.0299 & 4 & 0.6122 & 1.4793 & 0.2540 & 0.0786 \\
\hline Wealth-Income & 1 & 0.0585 & 0.4846 & 0.1970 & 0.0033 & 2 & 0.1447 & 0.6262 & 0.2190 & 0.0104 & 4 & 0.2067 & 0.4384 & 0.2620 & 0.0097 \\
\hline RiskFree-MMR/TBL & 1 & -0.1013 & -0.8489 & 0.7290 & 0.0100 & 2 & -0.2325 & -1.1166 & 0.7550 & 0.0263 & 4 & -0.5746 & -1.5621 & 0.8160 & 0.0705 \\
\hline Price-GDP & 1 & -0.2428 & -2.1087 & 0.9760 & 0.0589 & 2 & -0.4621 & -2.8976 & 0.9800 & 0.1086 & 4 & -0.8398 & -3.8147 & 0.9820 & 0.1652 \\
\hline CBRate & 1 & -0.1104 & -0.9257 & 0.7830 & 0.0119 & 2 & -0.2796 & -1.3772 & 0.8170 & 0.0380 & 4 & -0.6255 & -1.7567 & 0.8600 & 0.0835 \\
\hline VIX & 1 & 0.0711 & 0.6266 & 0.3170 & 0.0055 & 2 & 0.1321 & 0.8189 & 0.3020 & 0.0083 & 4 & 0.0000 & 0.0000 & 0.5910 & 0.0000 \\
\hline Intl Net Bank Claims & 1 & 0.0135 & 0.1188 & 0.8820 & 0.0002 & 2 & -0.0177 & -0.1111 & 0.4290 & 0.0002 & 4 & -0.1636 & -0.4897 & 0.5290 & 0.0070 \\
\hline Intl Bank Claims & 1 & -0.0071 & -0.0613 & 0.4850 & 0.0000 & 2 & -0.0626 & -0.3335 & 0.5630 & 0.0018 & 4 & -0.2789 & -0.7469 & 0.6830 & 0.0176 \\
\hline G7 Output Gap & 1 & -0.0952 & -0.8344 & 0.8060 & 0.0097 & 2 & -0.1497 & -0.7091 & 0.7170 & 0.010 & 4 & -0.1242 & -0.3387 & 0.6130 & 0.0039 \\
\hline
\end{tabular}

Notes: Table 3 shows results of in-sample predictive regressions for one quarter (Horizon =1), two quarter (Horizon=2) and four quarter (Horizon=4) returns. See Table 1 for variable descriptions. Slope is the slope coefficient on the predictor variable, $t$ is the $t$-statistic based on Newey-West procedure, $p(t)$ is the one-sided p-value estimated from the bootstrap procedure described in section 3.2 of the text. R-sq is the goodness of fit. Bold type is used to demonstrate significance at the $10 \%$ level; for the bootstrapped $\mathrm{p}$-value this occurs when $\mathrm{p}(\mathrm{t})$ is greater than 0.95 or less than 0.05 . 
Table 4: In-sample forecast regressions - Russia.

Panel A: Domestic Predictors

\begin{tabular}{|c|c|c|c|c|c|c|c|c|c|c|c|c|c|c|c|}
\hline \multirow[t]{2}{*}{ 1995Q1-2013Q2 } & \multicolumn{4}{|c|}{ One quarter ahead } & \multicolumn{5}{|c|}{ Two quarters ahead } & \multicolumn{6}{|c|}{ Four quarters ahead } \\
\hline & Horizon & Slope & $\mathrm{t}$ & $\mathrm{p}(\mathrm{t})$ & R-sq & Horizon & Slope & $\mathrm{t}$ & $\mathrm{p}(\mathrm{t})$ & R-sq & Horizon & Slope & $\mathrm{t}$ & $p(t)$ & R-sq \\
\hline Inflation-Inf & 1 & 0.1292 & 1.1086 & 0.1550 & 0.0170 & 2 & 0.2397 & 1.1802 & 0.1830 & 0.0270 & 4 & 0.5945 & 2.5449 & 0.0480 & 0.0903 \\
\hline OutputGaptoGDP & 1 & -0.3458 & -3.1460 & 1.0000 & 0.1223 & 2 & -0.6522 & -4.4872 & 1.0000 & 0.2012 & 4 & -1.0807 & -3.8602 & 0.9920 & 0.3018 \\
\hline M2Growth & 1 & 0.1058 & 0.8418 & 0.1450 & 0.0119 & 2 & 0.0627 & 0.3280 & 0.2910 & 0.0019 & 4 & -0.2328 & -1.8103 & 0.8350 & 0.0232 \\
\hline CommodityIndexGrowth & 1 & -0.1201 & -1.0293 & 0.8320 & 0.0147 & 2 & -0.2298 & -0.8313 & 0.7210 & 0.0247 & 4 & -0.3190 & -0.8955 & 0.7280 & 0.0258 \\
\hline FXchange & 1 & -0.2487 & -2.1888 & 0.9830 & 0.0632 & 2 & -0.4286 & -2.5055 & 0.9740 & 0.0866 & 4 & -0.6976 & -3.1025 & 0.9750 & 0.1252 \\
\hline CAY & 1 & 0.0097 & 0.0760 & 0.4590 & 0.0001 & 2 & 0.0584 & 0.1953 & 0.4600 & 0.0015 & 4 & 0.2690 & 0.8514 & 0.2700 & 0.0172 \\
\hline Wealth-Income & 1 & -0.0334 & -0.2614 & 0.5910 & 0.0010 & 2 & -0.1299 & -0.7538 & 0.7530 & 0.0073 & 4 & -0.5107 & -2.1801 & 0.9170 & 0.0620 \\
\hline RiskFree-MMR/TBL & 1 & 0.1078 & 0.9241 & 0.1750 & 0.0119 & 2 & 0.0740 & 0.8414 & 0.3260 & 0.0026 & 4 & 0.2262 & 1.2194 & 0.2500 & 0.0132 \\
\hline Price-GDP & 1 & 0.1041 & 0.8527 & 0.1650 & 0.0106 & 2 & 0.1866 & 0.6836 & 0.2370 & 0.0151 & 4 & 0.2298 & 0.5495 & 0.3040 & 0.0119 \\
\hline CBRate & 1 & 0.0633 & 0.5393 & 0.3370 & 0.0041 & 2 & 0.1974 & 1.2625 & 0.1870 & 0.0183 & 4 & 0.6110 & 2.7161 & 0.0360 & 0.0949 \\
\hline
\end{tabular}

Panel B: US and Global Predictors

\begin{tabular}{lcccccccccccccccc}
\hline 1995Q1-2013Q2 & \multicolumn{4}{c}{ One quarter ahead } & \multicolumn{4}{c}{ Two quarters ahead } & \multicolumn{4}{c}{ Four quarters ahead } \\
& Horizon & Slope & $\mathrm{t}$ & $\mathrm{p}(\mathrm{t})$ & $\mathrm{R}$-sq & Horizon & Slope & $\mathrm{t}$ & $\mathrm{p}(\mathrm{t})$ & $\mathrm{R}$-sq & Horizon & Slope & $\mathrm{t}$ & $\mathrm{p}(\mathrm{t})$ & $\mathrm{R}-\mathrm{sq}$ \\
\hline Inflation-Inf & 1 & 0.0450 & 0.3784 & 0.3620 & 0.0020 & 2 & 0.1094 & 0.5086 & 0.3320 & 0.0055 & 4 & 0.1565 & 0.6549 & 0.3080 & 0.0061 \\
OutputGaptoGDP & 1 & -0.1634 & -1.3887 & 0.8800 & 0.0268 & 2 & -0.3372 & $-\mathbf{2 . 1 4 7 9}$ & 0.9380 & 0.0522 & 4 & -0.5911 & $-\mathbf{2 . 2 9 9 7}$ & 0.9090 & 0.0862 \\
M2Growth & 1 & -0.0323 & -0.2754 & 0.6240 & 0.0011 & 2 & -0.0435 & -0.2798 & 0.6000 & 0.0009 & 4 & 0.0166 & 0.0869 & 0.5190 & 0.0001 \\
CommodityIndexGrowth & 1 & -0.1009 & -0.8641 & 0.8070 & 0.0104 & 2 & -0.2228 & -1.1753 & 0.8460 & 0.0235 & 4 & -0.3006 & -1.4026 & 0.8610 & 0.0234 \\
FXchange & 1 & -0.2142 & -1.8703 & 0.9610 & 0.0470 & 2 & -0.2243 & -1.3872 & 0.8950 & 0.0232 & 4 & -0.1224 & -0.3807 & 0.6330 & 0.0037 \\
CAY & 1 & 0.0428 & 0.3569 & 0.4900 & 0.0018 & 2 & 0.1331 & 0.5923 & 0.4700 & 0.0080 & 4 & 0.2987 & 0.9054 & 0.3830 & 0.0206 \\
Wealth-Income & 1 & -0.1227 & -1.0322 & 0.7450 & 0.0150 & 2 & -0.2110 & -1.3166 & 0.7580 & 0.0205 & 4 & -0.3811 & -1.1407 & 0.6620 & 0.0365 \\
RiskFree-MMR/TBL & 1 & 0.0078 & 0.0658 & 0.2800 & 0.0001 & 2 & 0.0011 & 0.0053 & 0.3500 & 0.0000 & 4 & -0.0119 & -0.0375 & 0.3520 & 0.0000 \\
Price-GDP & 1 & -0.1295 & -1.1126 & 0.8420 & 0.0171 & 2 & -0.1940 & -1.0111 & 0.7310 & 0.0178 & 4 & -0.3606 & -1.2277 & 0.7400 & 0.0336 \\
CBRate & 1 & 0.0450 & 0.3784 & 0.3620 & 0.0020 & 2 & 0.1094 & 0.5086 & 0.3320 & 0.0055 & 4 & 0.1565 & 0.6549 & 0.3080 & 0.0061 \\
VIX & 1 & 0.1011 & 0.8643 & 0.2510 & 0.0104 & 2 & 0.1503 & 1.0860 & 0.2450 & 0.0104 & 4 & 0.0546 & 0.2119 & 0.5290 & 0.0007 \\
Intl Net Bank Claims & 1 & -0.0264 & -0.2242 & 0.4770 & 0.0007 & 2 & -0.0854 & -0.9068 & 0.6770 & 0.0034 & 4 & -0.3651 & -1.4578 & 0.7610 & 0.0334 \\
Intl Bank Claims & 1 & -0.0870 & -0.7318 & 0.7720 & 0.0075 & 2 & -0.2274 & -1.4813 & 0.8520 & 0.0226 & 4 & -0.5310 & -1.5814 & 0.8530 & 0.0612 \\
G7 Output Gap & 1 & -0.1502 & -1.2827 & 0.9040 & 0.0226 & 2 & -0.2685 & -1.5545 & 0.8880 & 0.0327 & 4 & -0.3800 & -1.3074 & 0.8050 & 0.0350 \\
\hline \hline
\end{tabular}

Notes: Table 4 shows results of in-sample predictive regressions for one quarter (Horizon =1), two quarter (Horizon=2) and four quarter (Horizon=4) returns. See Table 1 for variable descriptions. Slope is the slope coefficient on the output gap, $t$ is the $t$-statistic based on Newey-West procedure, $\mathrm{p}(\mathrm{t})$ is the one-sided p-value estimated from the bootstrap procedure described in section 3.2 of the text. $\mathrm{R}$-sq is the goodness of fit. Bold type is used to demonstrate significance at the $10 \%$ level; for the bootstrapped $p$-value this occurs when $p(t)$ is greater than 0.95 or less than 0.05 . 
Table 5: In-sample forecast regressions - India.

Panel A: Domestic Predictors

\begin{tabular}{|c|c|c|c|c|c|c|c|c|c|c|c|c|c|c|c|}
\hline \multirow[t]{2}{*}{ 1995Q1-2013Q2 } & \multicolumn{4}{|c|}{ One quarter ahead } & \multicolumn{5}{|c|}{ Two quarters ahead } & \multicolumn{6}{|c|}{ Four quarters ahead } \\
\hline & Horizon & Slope & $\mathrm{t}$ & $\mathrm{p}(\mathrm{t})$ & R-sq & Horizon & Slope & $\mathrm{t}$ & $\mathrm{p}(\mathrm{t})$ & R-sq & Horizon & Slope & $\mathrm{t}$ & $p(t)$ & R-sq \\
\hline Inflation-Inf & 1 & 0.0302 & 0.2561 & 0.4490 & 0.0009 & 2 & 0.1364 & 0.7629 & 0.3070 & 0.0079 & 4 & 0.3343 & 0.7316 & 0.3570 & 0.0246 \\
\hline OutputGaptoGDP & 1 & 0.0094 & 0.0669 & 0.4440 & 0.0001 & 2 & -0.1389 & -0.6130 & 0.6510 & 0.0060 & 4 & -0.4071 & -0.7913 & 0.7080 & 0.0236 \\
\hline M2Growth & 1 & -0.0655 & -0.4888 & 0.6810 & 0.0040 & 2 & -0.0702 & -0.2328 & 0.5940 & 0.0019 & 4 & -0.2282 & -0.4482 & 0.6400 & 0.0094 \\
\hline CommodityIndexGrowth & 1 & -0.3044 & -2.7219 & 0.9950 & 0.0945 & 2 & -0.5222 & -1.9009 & 0.9220 & 0.1189 & 4 & -0.5693 & -1.5377 & 0.8530 & 0.0737 \\
\hline FXchange & 1 & -0.0952 & -0.8153 & 0.7600 & 0.0093 & 2 & -0.2327 & -0.9298 & 0.7560 & 0.0236 & 4 & -0.3980 & -0.9462 & 0.7190 & 0.0357 \\
\hline CAY & 1 & -0.0835 & -0.6170 & 0.7780 & 0.0063 & 2 & -0.1288 & -0.4842 & 0.6790 & 0.0063 & 4 & 0.2661 & 0.6304 & 0.3430 & 0.0140 \\
\hline Wealth-Income & 1 & -0.0301 & -0.2220 & 0.5880 & 0.0008 & 2 & -0.0254 & -0.0927 & 0.5250 & 0.0002 & 4 & -0.4173 & -1.1436 & 0.7550 & 0.0350 \\
\hline RiskFree-MMR/TBL & 1 & -0.0961 & -0.8232 & 0.8140 & 0.0095 & 2 & -0.0357 & -0.1946 & 0.5880 & 0.0006 & 4 & -0.2410 & -1.0706 & 0.7990 & 0.0135 \\
\hline Price-GDP & 1 & -0.1459 & -1.1874 & 0.6200 & 0.0212 & 2 & -0.3586 & -1.5335 & 0.6300 & 0.0540 & 4 & -0.7016 & -1.9262 & 0.6710 & 0.1038 \\
\hline CBRate & 1 & -0.2347 & -2.0600 & 0.9820 & 0.0564 & 2 & -0.3977 & -2.2288 & 0.9590 & 0.0695 & 4 & -0.5535 & -2.1081 & 0.9180 & 0.0707 \\
\hline
\end{tabular}

Panel B: US and Global Predictors

\begin{tabular}{|c|c|c|c|c|c|c|c|c|c|c|c|c|c|c|c|}
\hline \multirow[t]{2}{*}{ 1995Q1-2013Q2 } & \multicolumn{4}{|c|}{ One quarter ahead } & \multicolumn{6}{|c|}{ Two quarters ahead } & \multicolumn{4}{|c|}{ Four quarters ahead } & \multirow[b]{2}{*}{ R-sq } \\
\hline & Horizon & Slope & $\mathrm{t}$ & $p(t)$ & R-sq & Horizon & Slope & $\mathrm{t}$ & $p(t)$ & R-sq & Horizon & Slope & $\mathrm{t}$ & $p(t)$ & \\
\hline Inflation-Inf & 1 & -0.0913 & -0.7712 & 0.7680 & 0.0083 & 2 & 0.0095 & 0.0384 & 0.5190 & 0.0000 & 4 & 0.0751 & 0.2132 & 0.4490 & 0.0013 \\
\hline OutputGaptoGDP & 1 & -0.2633 & -2.2888 & 0.9860 & 0.0696 & 2 & -0.5382 & -2.1757 & 0.9310 & 0.1239 & 4 & -0.8273 & -2.3995 & 0.9310 & 0.1511 \\
\hline M2Growth & 1 & 0.1011 & 0.8660 & 0.2060 & 0.0105 & 2 & 0.2403 & 1.0100 & 0.2090 & 0.0254 & 4 & 0.3259 & 1.0679 & 0.2300 & 0.0239 \\
\hline CommodityIndexGrowth & 1 & -0.1563 & -1.3500 & 0.9160 & 0.0250 & 2 & -0.5298 & -3.0399 & 0.9800 & 0.1236 & 4 & -0.6252 & -2.8758 & 0.9730 & 0.0905 \\
\hline FXchange & 1 & -0.0380 & -0.3244 & 0.6400 & 0.0015 & 2 & -0.0459 & -0.2546 & 0.6010 & 0.0009 & 4 & 0.1222 & 0.3256 & 0.4230 & 0.0033 \\
\hline CAY & 1 & 0.0279 & 0.2327 & 0.5330 & 0.0008 & 2 & 0.0966 & 0.4342 & 0.4940 & 0.0039 & 4 & 0.3220 & 0.7740 & 0.3720 & 0.0215 \\
\hline Wealth-Income & 1 & -0.0020 & -0.0164 & 0.3470 & 0.0000 & 2 & -0.0601 & -0.2653 & 0.4050 & 0.0015 & 4 & -0.1784 & -0.3839 & 0.4360 & 0.0072 \\
\hline RiskFree-MMR/TBL & 1 & -0.0665 & -0.5619 & 0.5770 & 0.0044 & 2 & -0.1788 & -0.8350 & 0.6360 & 0.0135 & 4 & -0.4566 & -1.2539 & 0.7140 & 0.0439 \\
\hline Price-GDP & 1 & -0.1603 & -1.3851 & 0.8960 & 0.0263 & 2 & -0.3223 & -1.1860 & 0.7580 & 0.0457 & 4 & -0.5637 & -1.4048 & 0.7830 & 0.0734 \\
\hline CBRate & 1 & -0.0997 & -0.8449 & 0.6920 & 0.0100 & 2 & -0.2280 & -1.0851 & 0.6680 & 0.0219 & 4 & -0.5377 & -1.4206 & 0.7260 & 0.0609 \\
\hline VIX & 1 & 0.0592 & 0.5045 & 0.3620 & 0.0036 & 2 & 0.2094 & 0.8582 & 0.3000 & 0.0189 & 4 & 0.3227 & 0.7907 & 0.3570 & 0.0233 \\
\hline Intl Net Bank Claims & 1 & -0.0664 & -0.5652 & 0.6460 & 0.0045 & 2 & -0.1806 & -0.7412 & 0.6140 & 0.0142 & 4 & -0.3944 & -0.8732 & 0.6680 & 0.0349 \\
\hline Intl Bank Claims & 1 & -0.1349 & -1.1416 & 0.8370 & 0.0180 & 2 & -0.2376 & -0.9735 & 0.7370 & 0.0230 & 4 & -0.4680 & -1.0364 & 0.7240 & 0.0425 \\
\hline G7 Output Gap & 1 & -0.1679 & -1.4387 & 0.9300 & 0.0283 & 2 & -0.2477 & -1.0933 & 0.8450 & 0.0259 & 4 & -0.2345 & -0.6656 & 0.7220 & 0.0119 \\
\hline
\end{tabular}

Notes: Table 5 shows results of in-sample predictive regressions for one quarter (Horizon =1), two quarter (Horizon=2) and four quarter (Horizon=4) returns. See Table 1 for variable descriptions. Slope is the slope coefficient on the output gap, $t$ is the $t$-statistic based on Newey-West procedure, $\mathrm{p}(\mathrm{t})$ is the one-sided p-value estimated from the bootstrap procedure described in section 3.2 of the text. $\mathrm{R}$-sq is the goodness of fit. Bold type is used to demonstrate significance at the $10 \%$ level; for the bootstrapped $p$-value this occurs when $p(t)$ is greater than 0.95 or less than 0.05 . 
Panel A: Domestic Predictors

Table 6: In-sample forecast regressions - China.

\begin{tabular}{|c|c|c|c|c|c|c|c|c|c|c|c|c|c|c|c|}
\hline \multirow[t]{2}{*}{ 1995Q1-2013Q2 } & \multicolumn{4}{|c|}{ One quarter ahead } & \multicolumn{5}{|c|}{ Two quarters ahead } & \multicolumn{6}{|c|}{ Four quarters ahead } \\
\hline & Horizon & Slope & $\mathrm{t}$ & $\mathrm{p}(\mathrm{t})$ & R-sq & Horizon & Slope & $\mathrm{t}$ & $\mathrm{p}(\mathrm{t})$ & R-sq & Horizon & Slope & $\mathrm{t}$ & $\mathrm{p}(\mathrm{t})$ & R-sq \\
\hline Inflation-Inf & 1 & -0.0701 & -0.5921 & 0.6940 & 0.0049 & 2 & -0.1464 & -0.9676 & 0.7740 & 0.0109 & 4 & -0.1711 & -0.6588 & 0.6510 & 0.0069 \\
\hline OutputGaptoGDP & 1 & -0.2143 & -1.6993 & 0.9680 & 0.0425 & 2 & -0.5156 & -3.0203 & 0.9980 & 0.1248 & 4 & -1.1061 & -4.2143 & 0.9950 & 0.2634 \\
\hline M2Growth & 1 & 0.1761 & 1.3442 & 0.0570 & 0.0297 & 2 & 0.2357 & 1.7918 & 0.0530 & 0.0281 & 4 & 0.2660 & 1.2005 & 0.1600 & 0.0186 \\
\hline CommodityIndexGrowth & 1 & -0.1223 & -1.0364 & 0.8350 & 0.0149 & 2 & -0.1686 & -0.6939 & 0.6980 & 0.0143 & 4 & 0.0274 & 0.0776 & 0.4900 & 0.0002 \\
\hline FXchange & 1 & -0.0978 & -0.8263 & 0.8370 & 0.0095 & 2 & -0.1471 & -0.5524 & 0.7320 & 0.0110 & 4 & -0.2102 & -0.5234 & 0.7000 & 0.0102 \\
\hline CAY & 1 & 0.0407 & 0.2948 & 0.3830 & 0.0013 & 2 & 0.1371 & 0.4347 & 0.3710 & 0.0066 & 4 & 0.9974 & 2.1687 & 0.0760 & 0.1094 \\
\hline Wealth-Income & 1 & -0.1335 & -0.9938 & 0.8320 & 0.0150 & 2 & -0.3279 & -1.2553 & 0.8450 & 0.0410 & 4 & -1.1786 & -2.8452 & 0.9590 & 0.1900 \\
\hline RiskFree-MMR/TBL & 1 & -0.0922 & -0.7727 & 0.7840 & 0.0083 & 2 & -0.2119 & -1.1691 & 0.8420 & 0.0220 & 4 & -0.5890 & -1.9360 & 0.9100 & 0.0751 \\
\hline Price-GDP & 1 & -0.1051 & -0.8324 & 0.7150 & 0.0104 & 2 & -0.1587 & -0.6585 & 0.5830 & 0.0120 & 4 & -0.2506 & -0.5764 & 0.5490 & 0.0135 \\
\hline CBRate & 1 & -0.1418 & -1.2061 & 0.8790 & 0.0201 & 2 & -0.2996 & -1.3701 & 0.8410 & 0.0455 & 4 & -0.5335 & -1.2088 & 0.7680 & 0.0663 \\
\hline
\end{tabular}

Panel B: US and Global Predictors

\begin{tabular}{|c|c|c|c|c|c|c|c|c|c|c|c|c|c|c|c|}
\hline \multirow[t]{2}{*}{ 1995Q1-2013Q2 } & \multicolumn{4}{|c|}{ One quarter ahead } & \multirow[b]{2}{*}{ R-sq } & \multicolumn{4}{|c|}{ Two quarters ahead } & \multicolumn{6}{|c|}{ Four quarters ahead } \\
\hline & Horizon & Slope & $\mathrm{t}$ & $p(t)$ & & Horizon & Slope & $\mathrm{t}$ & $p(t)$ & R-sq & Horizon & Slope & $\mathrm{t}$ & $\mathrm{p}(\mathrm{t})$ & R-sq \\
\hline Inflation-Inf & 1 & 0.1459 & 1.2257 & 0.1260 & 0.0207 & 2 & 0.2792 & 1.1313 & 0.1930 & 0.0384 & 4 & 0.4089 & 1.1872 & 0.2130 & 0.0378 \\
\hline OutputGaptoGDP & 1 & -0.2036 & -1.7255 & 0.9390 & 0.0408 & 2 & -0.3580 & -1.6815 & 0.8760 & 0.0635 & 4 & -0.6448 & -1.9431 & 0.8860 & 0.0931 \\
\hline M2Growth & 1 & -0.0029 & -0.0241 & 0.4920 & 0.0000 & 2 & 0.0716 & 0.3979 & 0.3820 & 0.0026 & 4 & 0.0033 & 0.0126 & 0.5230 & 0.0000 \\
\hline CommodityIndexGrowth & 1 & -0.1037 & -0.8791 & 0.8100 & 0.0108 & 2 & -0.3314 & -2.1622 & 0.9370 & 0.0559 & 4 & -0.2348 & -0.9148 & 0.7420 & 0.0129 \\
\hline FXchange & 1 & -0.0058 & -0.0487 & 0.5580 & 0.0000 & 2 & -0.0543 & -0.3218 & 0.6210 & 0.0015 & 4 & -0.0431 & -0.1267 & 0.5940 & 0.0004 \\
\hline CAY & 1 & 0.1247 & 1.0372 & 0.2660 & 0.0151 & 2 & 0.2478 & 1.0867 & 0.3020 & 0.0299 & 4 & 0.6122 & 1.4793 & 0.2540 & 0.0786 \\
\hline Wealth-Income & 1 & 0.0585 & 0.4846 & 0.1970 & 0.0033 & 2 & 0.1447 & 0.6262 & 0.2190 & 0.0104 & 4 & 0.2067 & 0.4384 & 0.2620 & 0.0097 \\
\hline RiskFree-MMR/TBL & 1 & -0.1013 & -0.8489 & 0.7290 & 0.0100 & 2 & -0.2325 & -1.1166 & 0.7550 & 0.0263 & 4 & -0.5746 & -1.5621 & 0.8160 & 0.0705 \\
\hline Price-GDP & 1 & -0.2428 & -2.1087 & 0.9760 & 0.0589 & 2 & -0.4621 & -2.8976 & 0.9800 & 0.1086 & 4 & -0.8398 & -3.8147 & 0.9820 & 0.1652 \\
\hline CBRate & 1 & -0.1104 & -0.9257 & 0.7830 & 0.0119 & 2 & -0.2796 & -1.3772 & 0.8170 & 0.0380 & 4 & -0.6255 & -1.7567 & 0.8600 & 0.0835 \\
\hline VIX & 1 & 0.0198 & 0.1672 & 0.4920 & 0.0004 & 2 & -0.0196 & -0.0907 & 0.5500 & 0.0002 & 4 & -0.0506 & -0.1167 & 0.6260 & 0.0006 \\
\hline Intl Net Bank Claims & 1 & -0.0150 & -0.1260 & 0.4800 & 0.0002 & 2 & -0.0842 & -0.3788 & 0.5510 & 0.0036 & 4 & -0.2060 & -0.4991 & 0.5730 & 0.0097 \\
\hline Intl Bank Claims & 1 & -0.0175 & -0.1449 & 0.5540 & 0.0003 & 2 & -0.1215 & -0.5083 & 0.6530 & 0.0069 & 4 & -0.2214 & -0.5061 & 0.6710 & 0.0097 \\
\hline G7 Output Gap & 1 & -0.0964 & -0.8086 & 0.8220 & 0.0091 & 2 & -0.1439 & -0.7455 & 0.7680 & 0.0100 & 4 & -0.1041 & -0.3619 & 0.6140 & 0.0024 \\
\hline
\end{tabular}

Notes: Table 6 shows results of in-sample predictive regressions for one quarter (Horizon =1), two quarter (Horizon=2) and four quarter (Horizon=4) returns. See Table 1 for variable descriptions. Slope is the slope coefficient on the output gap, $t$ is the t-statistic based on Newey-West procedure, $p(t)$ is the one-sided p-value estimated from the bootstrap procedure described in section 3.2 of the text. R-sq is the goodness of fit. Bold type is used to demonstrate significance at the $10 \%$ level; for the bootstrapped p-value this occurs when p(t) is greater than 0.95 or less than 0.05 . 
Panel A: Domestic Predictors

Table 7: In-sample forecast regressions - South Africa.

\begin{tabular}{|c|c|c|c|c|c|c|c|c|c|c|c|c|c|c|c|}
\hline \multirow[t]{2}{*}{ 1995Q1-2013Q2 } & \multicolumn{4}{|c|}{ One quarter ahead } & \multicolumn{5}{|c|}{ Two quarters ahead } & \multicolumn{6}{|c|}{ Four quarters ahead } \\
\hline & Horizon & Slope & $\mathrm{t}$ & $\mathrm{p}(\mathrm{t})$ & R-sq & Horizon & Slope & $\mathrm{t}$ & $\mathrm{p}(\mathrm{t})$ & R-sq & Horizon & Slope & $\mathrm{t}$ & $\mathrm{p}(\mathrm{t})$ & R-sq \\
\hline Inflation-Inf & 1 & -0.2384 & -2.0923 & 0.9860 & 0.0581 & 2 & -0.3282 & -1.8909 & 0.9560 & 0.0578 & 4 & -0.4801 & -1.6758 & 0.9290 & 0.0685 \\
\hline OutputGaptoGDP & 1 & -0.2875 & -2.5605 & 0.9910 & 0.0845 & 2 & -0.5461 & -4.2336 & 0.9990 & 0.1601 & 4 & -0.9643 & -4.2670 & 0.9930 & 0.2789 \\
\hline M2Growth & 1 & -0.1333 & -1.1429 & 0.8560 & 0.0181 & 2 & -0.2703 & -1.8658 & 0.9080 & 0.0382 & 4 & -0.5828 & -1.8752 & 0.8880 & 0.0939 \\
\hline CommodityIndexGrowth & 1 & -0.0823 & -0.7019 & 0.7660 & 0.0069 & 2 & -0.0749 & -0.3176 & 0.6010 & 0.0030 & 4 & 0.0820 & 0.1979 & 0.4240 & 0.0020 \\
\hline FXchange & 1 & 0.0883 & 0.7533 & 0.2230 & 0.0079 & 2 & 0.1949 & 1.2162 & 0.1330 & 0.0202 & 4 & 0.3805 & 1.1818 & 0.1730 & 0.0429 \\
\hline CAY & 1 & -0.0117 & -0.0909 & 0.5260 & 0.0001 & 2 & 0.0131 & 0.0731 & 0.4570 & 0.0001 & 4 & 0.2967 & 1.1049 & 0.2060 & 0.0212 \\
\hline Wealth-Income & 1 & 0.0644 & 0.5058 & 0.3240 & 0.0039 & 2 & 0.1707 & 0.8281 & 0.2480 & 0.0144 & 4 & -0.0893 & -0.2542 & 0.5870 & 0.0022 \\
\hline RiskFree-MMR/TBL & 1 & -0.1705 & -1.4569 & 0.9640 & 0.0290 & 2 & -0.2554 & -1.3513 & 0.9370 & 0.0333 & 4 & -0.4529 & -1.2737 & 0.9040 & 0.0551 \\
\hline Price-GDP & 1 & -0.0578 & -0.4857 & 0.4440 & 0.0033 & 2 & -0.0844 & -0.4844 & 0.4370 & 0.0036 & 4 & -0.1005 & -0.3080 & 0.3480 & 0.0027 \\
\hline CBRate & 1 & -0.1905 & -1.6318 & 0.9780 & 0.0362 & 2 & -0.2711 & -1.3833 & 0.9240 & 0.0374 & 4 & -0.4433 & -1.2168 & 0.8920 & 0.0527 \\
\hline
\end{tabular}

Panel B: US and Global Predictors

\begin{tabular}{|c|c|c|c|c|c|c|c|c|c|c|c|c|c|c|c|}
\hline \multirow[t]{2}{*}{ 1995Q1-2013Q2 } & \multicolumn{4}{|c|}{ One quarter ahead } & \multirow[b]{2}{*}{ R-sq } & \multicolumn{4}{|c|}{ Two quarters ahead } & \multicolumn{6}{|c|}{ Four quarters ahead } \\
\hline & Horizon & Slope & $\mathrm{t}$ & $p(t)$ & & Horizon & Slope & $\mathrm{t}$ & $p(t)$ & R-sq & Horizon & Slope & $\mathrm{t}$ & $p(t)$ & R-sq \\
\hline Inflation-Inf & 1 & 0.0597 & 0.5030 & 0.2710 & 0.0036 & 2 & 0.2625 & 1.2252 & 0.1370 & 0.0358 & 4 & 0.5140 & 1.5275 & 0.1230 & 0.0763 \\
\hline OutputGaptoGDP & 1 & -0.0737 & -0.6194 & 0.6410 & 0.0055 & 2 & -0.1561 & -0.9804 & 0.6890 & 0.0128 & 4 & -0.2443 & -0.7990 & 0.6340 & 0.0171 \\
\hline M2Growth & 1 & 0.0596 & 0.5090 & 0.3140 & 0.0036 & 2 & 0.0036 & 0.0222 & 0.5380 & 0.0000 & 4 & -0.0368 & -0.1412 & 0.5620 & 0.0004 \\
\hline CommodityIndexGrowth & 1 & -0.0444 & -0.3791 & 0.6390 & 0.0020 & 2 & -0.1180 & -0.7614 & 0.7670 & 0.0075 & 4 & -0.1309 & -0.5153 & 0.6630 & 0.0051 \\
\hline FXchange & 1 & -0.0485 & -0.4140 & 0.6500 & 0.0024 & 2 & -0.0438 & -0.3183 & 0.6180 & 0.0010 & 4 & -0.0837 & -0.3301 & 0.6270 & 0.0020 \\
\hline CAY & 1 & 0.0421 & 0.3516 & 0.5450 & 0.0018 & 2 & 0.0959 & 0.5487 & 0.5020 & 0.0047 & 4 & 0.2041 & 0.7778 & 0.4650 & 0.0112 \\
\hline Wealth-Income & 1 & 0.0469 & 0.3919 & 0.1790 & 0.0022 & 2 & 0.1242 & 0.7594 & 0.1130 & 0.0081 & 4 & 0.2089 & 0.5542 & 0.1760 & 0.0127 \\
\hline RiskFree-MMR/TBL & 1 & -0.0164 & -0.1381 & 0.4520 & 0.0003 & 2 & -0.0392 & -0.2540 & 0.4660 & 0.0008 & 4 & -0.1837 & -0.7214 & 0.5920 & 0.0092 \\
\hline Price-GDP & 1 & -0.0492 & -0.4193 & 0.6110 & 0.0025 & 2 & -0.0756 & -0.5248 & 0.6370 & 0.0031 & 4 & -0.1608 & -0.7974 & 0.6720 & 0.0077 \\
\hline CBRate & 1 & -0.0158 & -0.1330 & 0.5370 & 0.0002 & 2 & -0.0566 & -0.3760 & 0.6070 & 0.0016 & 4 & -0.2281 & -0.8569 & 0.7070 & 0.0142 \\
\hline VIX & 1 & -0.0196 & -0.1665 & 0.6190 & 0.0004 & 2 & -0.0714 & -0.3662 & 0.6950 & 0.0027 & 4 & -0.1147 & -0.3799 & 0.7110 & 0.0038 \\
\hline Intl Net Bank Claims & 1 & 0.0126 & 0.1072 & 0.4040 & 0.0002 & 2 & -0.0168 & -0.1146 & 0.4560 & 0.0002 & 4 & -0.1763 & -0.5329 & 0.5930 & 0.0090 \\
\hline Intl Bank Claims & 1 & 0.0195 & 0.1636 & 0.4630 & 0.0004 & 2 & 0.0108 & 0.0636 & 0.4850 & 0.0000 & 4 & -0.0809 & -0.2034 & 0.5990 & 0.0016 \\
\hline G7 Output Gap & 1 & -0.0933 & -0.7912 & 0.7630 & 0.0087 & 2 & -0.1400 & -0.8874 & 0.7570 & 0.0101 & 4 & -0.1317 & -0.4534 & 0.6170 & 0.0049 \\
\hline
\end{tabular}

Notes: Table 7 shows results of in-sample predictive regressions for one quarter (Horizon =1), two quarter (Horizon=2) and four quarter (Horizon=4) returns. See Table 1 for variable descriptions. Slope is the slope coefficient on the output gap, $t$ is the t-statistic based on Newey-West procedure, $\mathrm{p}(\mathrm{t})$ is the one-sided p-value estimated from the bootstrap procedure described in section 3.2 of the text. R-sq is the goodness of fit. Bold type is used to demonstrate significance at the $10 \%$ level; for the bootstrapped p-value this occurs when $\mathrm{p}(\mathrm{t})$ is greater than 0.95 or less than 0.05 . 
Table 8: Out-of-sample forecast regressions - Brazil.

Panel A: Domestic Predictors

1995Q1-2004Q4 INS One quarter ahead Two quarters ahead Four quarters ahead

1995Q1-2004Q4 INS One quarter ahead Two quarters ahead Four quarters ahead

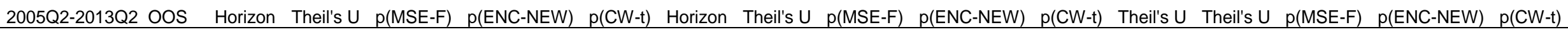

\begin{tabular}{|c|c|c|c|c|c|c|c|c|c|c|c|c|c|c|c|}
\hline Inflation-Inf & 1 & 0.9952 & 0.172 & 0.273 & 0.141 & 2 & 0.9942 & 0.192 & 0.315 & 0.202 & 4 & 0.9927 & 0.178 & 0.269 & 0.127 \\
\hline OutputGaptoGDP & 1 & 0.9138 & 0.002 & 0.004 & 0.012 & 2 & 0.8732 & 0.002 & 0.004 & 0.035 & 4 & 0.8693 & 0.012 & 0.014 & 0.039 \\
\hline M2Growth & 1 & 1.0008 & 0.246 & 0.39 & 0.453 & 2 & 0.9979 & 0.218 & 0.355 & 0.217 & 4 & 0.9955 & 0.211 & 0.335 & 0.078 \\
\hline CommodityIndexGrowth & 1 & 0.9873 & 0.095 & 0.087 & 0.143 & 2 & 1.0290 & 0.662 & 0.349 & 0.351 & 4 & 1.0216 & 0.504 & 0.474 & 0.451 \\
\hline FXchange & 1 & 0.9897 & 0.105 & 0.048 & 0.124 & 2 & 0.9754 & 0.079 & 0.052 & 0.128 & 4 & 0.9701 & 0.115 & 0.101 & 0.145 \\
\hline CAY & 1 & 0.9858 & 0.110 & 0.153 & 0.092 & 2 & 0.9950 & 0.239 & 0.282 & 0.22 & 4 & 1.0453 & 0.692 & 0.658 & 0.917 \\
\hline Wealth-Income & 1 & 1.0128 & 0.483 & 0.187 & 0.255 & 2 & 1.0741 & 0.815 & 0.843 & 0.549 & 4 & 1.2703 & 0.904 & 0.925 & 0.896 \\
\hline RiskFree-MMR/TBL & 1 & 0.9752 & 0.034 & 0.048 & 0.048 & 2 & 0.9735 & 0.095 & 0.131 & 0.12 & 4 & 0.9239 & 0.060 & 0.088 & 0.055 \\
\hline Price-GDP & 1 & 0.9984 & 0.246 & 0.065 & 0.160 & 2 & 1.0260 & 0.506 & 0.114 & 0.248 & 4 & 1.0162 & 0.388 & 0.129 & 0.251 \\
\hline CBRate & 1 & 0.9959 & 0.173 & 0.297 & 0.124 & 2 & 0.9874 & 0.160 & 0.241 & 0.101 & 4 & 0.8898 & 0.031 & 0.047 & 0.013 \\
\hline CAY_RT & 1 & 1.0377 & 0.776 & 0.821 & 0.687 & 2 & 1.1342 & 0.916 & 0.971 & 0.768 & 4 & 1.2848 & 0.893 & 0.893 & 0.591 \\
\hline Wealth-Income_RT & 1 & 1.0160 & 0.518 & 0.189 & 0.258 & 2 & 1.0884 & 0.852 & 0.849 & 0.53 & 4 & 1.2896 & 0.924 & 0.930 & 0.811 \\
\hline OutputGap_to_GDP_RT & 1 & 0.9612 & 0.036 & 0.059 & 0.025 & 2 & 0.9444 & 0.031 & 0.059 & 0.092 & 4 & 0.9493 & 0.092 & 0.089 & 0.134 \\
\hline
\end{tabular}

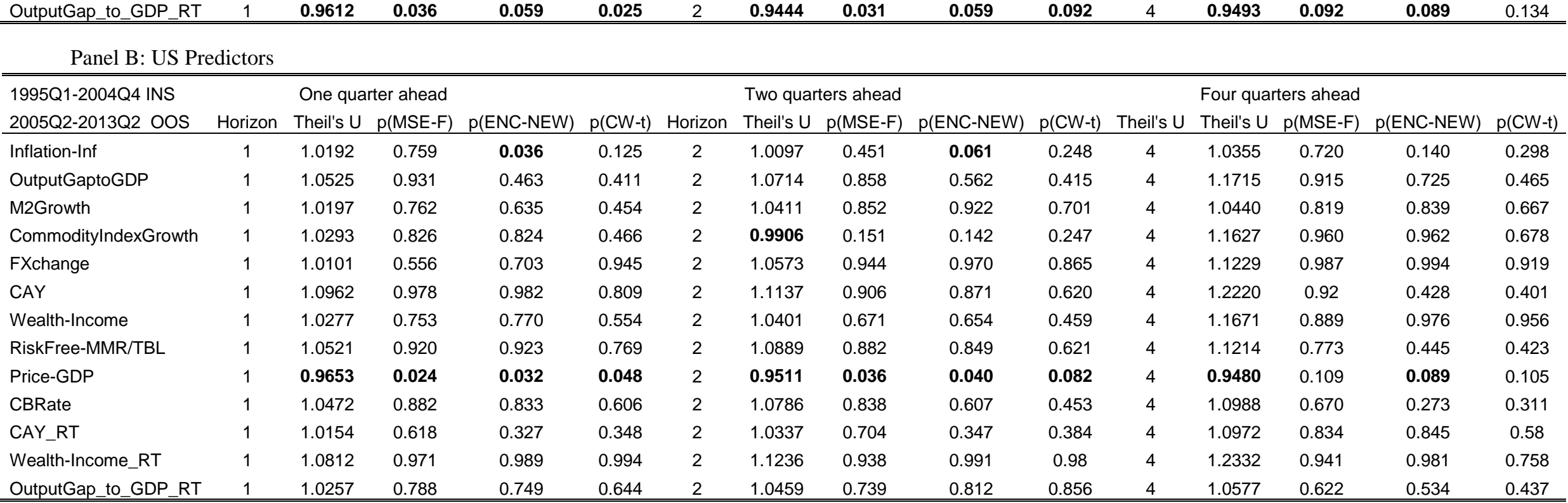


Panel C: Global Predictors

\begin{tabular}{|c|c|c|c|c|c|c|c|c|c|c|c|c|c|c|c|}
\hline \multirow[t]{2}{*}{ 1995Q1-2013Q2 } & \multicolumn{4}{|c|}{ One quarter ahead } & \multicolumn{5}{|c|}{ Two quarters ahead } & \multicolumn{5}{|c|}{ Four quarters ahead } & \multirow[b]{2}{*}{$\mathrm{p}(\mathrm{CW}-\mathrm{t})$} \\
\hline & Horizon & Theil's U & $p(M S E-F)$ & $\mathrm{p}(\mathrm{ENC}-\mathrm{NEW})$ & $\mathrm{p}(\mathrm{CW}-\mathrm{t})$ & Horizon & Theil's U & $\mathrm{p}(\mathrm{MSE}-\mathrm{F})$ & $\mathrm{p}(\mathrm{ENC}-\mathrm{NEW})$ & $p(C W-t)$ & Horizon & Theil's U & $\mathrm{p}(\mathrm{MSE}-\mathrm{F})$ & $\mathrm{p}(\mathrm{ENC}-\mathrm{NEW})$ & \\
\hline VIX & 1 & 1.0044 & 0.355 & 0.417 & 0.431 & 2 & 1.0121 & 0.464 & 0.561 & 0.568 & 4 & 1.0227 & 0.530 & 0.544 & 0.514 \\
\hline Intl Net Bank Claims & 1 & 1.0410 & 0.882 & 0.940 & 0.864 & 2 & 1.0975 & 0.924 & 0.952 & 0.942 & 4 & 1.3171 & 0.974 & 0.637 & 0.488 \\
\hline Intl Bank Claims & 1 & 1.0644 & 0.970 & 0.957 & 0.801 & 2 & 1.1099 & 0.947 & 0.882 & 0.708 & 4 & 1.1943 & 0.915 & 0.462 & 0.419 \\
\hline G7 Output Gap & 1 & 1.0782 & 0.968 & 0.092 & 0.195 & 2 & 1.1746 & 0.967 & 0.334 & 0.372 & 4 & 1.3756 & 0.965 & 0.748 & 0.516 \\
\hline G7 Output Gap RT & 1 & 1.1141 & 0.991 & 0.027 & 0.082 & 2 & 1.3597 & 0.993 & 0.084 & 0.181 & 4 & 2.0149 & 0.995 & 0.628 & 0.515 \\
\hline
\end{tabular}

Notes: Table 8 shows out-of-sample forecasting for returns at the one quarter, two quarter and four quarter horizons. Theil's U is the ratio of the forecast error of the regression model to that of the

historical average benchmark. MSE-F and CW-t are tests for equal forecast accuracy. ENC NEW tests for encompassing. The one-sided p-values for these tests are based on a bootstrapping procedure described in Section 3.2. Bold type is used to denote significance at the $10 \%$ level for a one-sided test. 
Table 9: Out-of-sample forecast regressions - Russia.

Panel A: Domestic Predictors

\begin{tabular}{|c|c|c|c|c|c|c|c|c|c|c|c|c|c|c|c|}
\hline \multirow{2}{*}{$\begin{array}{l}\text { 1995Q1-2004Q4 INS } \\
\text { 2005Q2-2013Q2 OOS }\end{array}$} & \multicolumn{4}{|c|}{ One quarter ahead } & \multicolumn{5}{|c|}{ Two quarters ahead } & \multicolumn{5}{|c|}{ Four quarters ahead } & \multirow[b]{2}{*}{$p(C W-t)$} \\
\hline & Horizon & Theil's U & $p(M S E-F)$ & $\mathrm{p}(\mathrm{ENC}-\mathrm{NEW})$ & $\mathrm{p}(\mathrm{CW}-\mathrm{t})$ & Horizon & Theil's U & $\mathrm{p}(\mathrm{MSE}-\mathrm{F})$ & $\mathrm{p}(\mathrm{ENC}-\mathrm{NEW})$ & $p(C W-t)$ & Theil's U & Theil's U & $\mathrm{p}(\mathrm{MSE}-\mathrm{F})$ & $\mathrm{p}(\mathrm{ENC}-\mathrm{NEW})$ & \\
\hline Inflation-Inf & 1 & 0.9952 & 0.163 & 0.230 & 0.223 & 2 & 0.9962 & 0.196 & 0.264 & 0.27 & 4 & 0.9706 & 0.14 & 0.179 & 0.215 \\
\hline OutputGaptoGDP & 1 & 0.8618 & 0.000 & 0.000 & 0.023 & 2 & 0.8025 & 0.000 & 0.000 & 0.075 & 4 & 0.8281 & 0.007 & 0.000 & 0.135 \\
\hline M2Growth & 1 & 1.0840 & 0.940 & 0.451 & 0.429 & 2 & 1.0674 & 0.813 & 0.814 & 0.603 & 4 & 1.0674 & 0.637 & 0.441 & 0.44 \\
\hline CommodityIndexGrowth & 1 & 1.0157 & 0.661 & 0.257 & 0.339 & 2 & 1.0695 & 0.901 & 0.874 & 0.492 & 4 & 1.0662 & 0.754 & 0.790 & 0.637 \\
\hline FXchange & 1 & 0.9792 & 0.059 & 0.065 & 0.075 & 2 & 0.9871 & 0.105 & 0.100 & 0.141 & 4 & 0.9670 & 0.149 & 0.176 & 0.197 \\
\hline CAY & 1 & 1.0097 & 0.489 & 0.632 & 0.715 & 2 & 1.0045 & 0.315 & 0.445 & 0.541 & 4 & 0.9921 & 0.224 & 0.325 & 0.294 \\
\hline Wealth-Income & 1 & 1.0059 & 0.407 & 0.542 & 0.836 & 2 & 1.0196 & 0.537 & 0.656 & 0.864 & 4 & 0.9989 & 0.265 & 0.285 & 0.309 \\
\hline RiskFree-MMR/TBL & 1 & 0.9941 & 0.122 & 0.210 & 0.199 & 2 & 0.9993 & 0.245 & 0.381 & 0.356 & 4 & 0.9904 & 0.173 & 0.279 & 0.244 \\
\hline Price-GDP & 1 & 1.0073 & 0.162 & 0.244 & 0.235 & 2 & 1.0572 & 0.468 & 0.557 & 0.633 & 4 & 1.2130 & 0.732 & 0.899 & 0.737 \\
\hline CBRate & 1 & 0.9970 & 0.182 & 0.332 & 0.246 & 2 & 0.9967 & 0.209 & 0.295 & 0.314 & 4 & 0.9729 & 0.124 & 0.121 & 0.215 \\
\hline CAY_RT & 1 & 1.0273 & 0.711 & 0.745 & 0.589 & 2 & 1.0810 & 0.839 & 0.908 & 0.670 & 4 & 1.1335 & 0.782 & 0.897 & 0.719 \\
\hline Wealth-Income_RT & 1 & 0.9995 & 0.238 & 0.315 & 0.302 & 2 & 1.0116 & 0.385 & 0.385 & 0.386 & 4 & 1.0019 & 0.254 & 0.184 & 0.261 \\
\hline OutputGap_to_GDP_RT & 1 & 1.0163 & 0.648 & 0.064 & 0.149 & 2 & 1.0131 & 0.426 & 0.061 & 0.140 & 4 & 1.1350 & 0.875 & 0.110 & 0.132 \\
\hline \multicolumn{16}{|c|}{ Panel B: US Predictors } \\
\hline 1995Q1-2004Q4 INS & \multicolumn{4}{|c|}{ One quarter ahead } & & \multicolumn{4}{|c|}{ Two quarters ahead } & \multicolumn{5}{|c|}{ Four quarters ahead } & \\
\hline 2005Q2-2013Q2 oOS & Horizon & Theil's U & $p(M S E-F)$ & $\mathrm{p}(\mathrm{ENC}-\mathrm{NEW})$ & $p(C W-t)$ & Horizon & Theil's U & $\mathrm{p}(\mathrm{MSE}-\mathrm{F})$ & $\mathrm{p}(\mathrm{ENC}-\mathrm{NEW})$ & $p(C W-t)$ & Theil's U & Theil's U & $\mathrm{p}(\mathrm{MSE}-\mathrm{F})$ & $\mathrm{p}(\mathrm{ENC}-\mathrm{NEW})$ & $p(C W-t)$ \\
\hline Inflation-Inf & 1 & 1.0726 & 0.976 & 0.812 & 0.532 & 2 & 1.0456 & 0.838 & 0.248 & 0.339 & 4 & 1.0310 & 0.696 & 0.243 & 0.293 \\
\hline OutputGaptoGDP & 1 & 0.9683 & 0.037 & 0.022 & 0.029 & 2 & 0.9588 & 0.047 & 0.023 & 0.086 & 4 & 0.9599 & 0.115 & 0.056 & 0.136 \\
\hline M2Growth & 1 & 1.0303 & 0.864 & 0.802 & 0.562 & 2 & 1.0349 & 0.803 & 0.734 & 0.511 & 4 & 1.0181 & 0.600 & 0.725 & 0.874 \\
\hline CommodityIndexGrowth & 1 & 1.0422 & 0.889 & 0.648 & 0.419 & 2 & 1.1344 & 0.981 & 0.984 & 0.567 & 4 & 1.1998 & 0.983 & 0.996 & 0.747 \\
\hline FXchange & 1 & 1.0454 & 0.941 & 0.052 & 0.216 & 2 & 1.0767 & 0.952 & 0.836 & 0.572 & 4 & 1.1550 & 0.99 & 0.994 & 0.952 \\
\hline CAY & 1 & 1.1264 & 0.989 & 0.996 & 0.867 & 2 & 1.1948 & 0.98 & 0.976 & 0.722 & 4 & 1.2395 & 0.924 & 0.488 & 0.466 \\
\hline Wealth-Income & 1 & 1.0877 & 0.977 & 0.922 & 0.639 & 2 & 1.0921 & 0.88 & 0.802 & 0.538 & 4 & 1.0830 & 0.671 & 0.519 & 0.456 \\
\hline RiskFree-MMR/TBL & 1 & 1.0357 & 0.791 & 0.924 & 0.859 & 2 & 1.0637 & 0.769 & 0.912 & 0.775 & 4 & 1.0589 & 0.561 & 0.713 & 0.674 \\
\hline Price-GDP & 1 & 1.0062 & 0.363 & 0.205 & 0.246 & 2 & 1.0033 & 0.258 & 0.272 & 0.271 & 4 & 1.0143 & 0.34 & 0.271 & 0.234 \\
\hline CBRate & 1 & 1.0262 & 0.715 & 0.875 & 0.824 & 2 & 1.0480 & 0.678 & 0.831 & 0.716 & 4 & 1.0346 & 0.419 & 0.511 & 0.547 \\
\hline CAY_RT & 1 & 1.1163 & 0.995 & 0.986 & 0.832 & 2 & 1.0776 & 0.906 & 0.93 & 0.794 & 4 & 1.0231 & 0.523 & 0.625 & 0.734 \\
\hline Wealth-Income_RT & 1 & 1.1851 & 0.997 & 0.996 & 0.912 & 2 & 1.2011 & 0.981 & 0.983 & 0.845 & 4 & 1.1216 & 0.786 & 0.621 & 0.556 \\
\hline OutputGap_to_GDP_RT & 1 & 1.0537 & 0.934 & 0.973 & 0.969 & 2 & 1.0860 & 0.896 & 0.960 & 0.840 & 4 & 1.0783 & 0.738 & 0.544 & 0.487 \\
\hline
\end{tabular}


Panel C: Global Predictors

\begin{tabular}{|c|c|c|c|c|c|c|c|c|c|c|c|c|c|c|c|}
\hline \multirow[t]{2}{*}{ 1995Q1-2013Q2 } & \multicolumn{4}{|c|}{ One quarter ahead } & \multicolumn{5}{|c|}{ Two quarters ahead } & \multicolumn{5}{|c|}{ Four quarters ahead } & \multirow[b]{2}{*}{$\mathrm{p}(\mathrm{CW}-\mathrm{t}$} \\
\hline & Horizon & Theil's U & $p(M S E-F)$ & $\mathrm{p}$ (ENC-NEW) & $\mathrm{p}(\mathrm{CW}-\mathrm{t})$ & Horizon & Theil's U & $\mathrm{p}(\mathrm{MSE}-\mathrm{F})$ & $\mathrm{p}(\mathrm{ENC}-\mathrm{NEW})$ & $p(C W-t)$ & Horizon & Theil's U & $\mathrm{p}$ (MSE-F) & $\mathrm{p}$ (ENC-NEW) & \\
\hline VIX & 1 & 1.0521 & 0.937 & 0.931 & 0.667 & 2 & 1.0333 & 0.765 & 0.795 & 0.615 & 4 & 1.0180 & 0.490 & 0.629 & 0.880 \\
\hline Intl Net Bank Claims & 1 & 1.0596 & 0.942 & 0.967 & 0.893 & 2 & 1.0787 & 0.852 & 0.881 & 0.770 & 4 & 1.3175 & 0.956 & 0.219 & 0.306 \\
\hline Intl Bank Claims & 1 & 1.1352 & 0.992 & 0.945 & 0.637 & 2 & 1.2045 & 0.982 & 0.506 & 0.405 & 4 & 1.1886 & 0.893 & 0.124 & 0.226 \\
\hline G7 Output Gap & 1 & 1.0543 & 0.922 & 0.012 & 0.051 & 2 & 1.1253 & 0.934 & 0.041 & 0.120 & 4 & 1.2172 & 0.900 & 0.128 & 0.180 \\
\hline G7 Output Gap RT & 1 & 1.1578 & 0.991 & 0.005 & 0.023 & 2 & 1.4656 & 0.996 & 0.036 & 0.098 & 4 & 1.8452 & 0.992 & 0.144 & 0.083 \\
\hline
\end{tabular}

Notes: Table 9 shows out-of-sample forecasting for returns at the one quarter, two quarter and four quarter horizons. Theil's $U$ is the ratio of the forecast error of the regression model to that of the historical average benchmark. MSE-F and CW-t are tests for equal forecast accuracy. ENC NEW tests for encompassing. The one-sided p-values for these tests are based on a bootstrapping procedure described in Section 3.2. Bold type is used to denote significance at the $10 \%$ level for a one-sided test. 
Table 10: Out-of-sample forecast regressions - India.

Panel A: Domestic Predictors

1995Q1-2004Q4 INS One quarter ahead Two quarters ahead

1995Q1-2004Q4 INS One quarter ahead Two quarters ahead Four quarters ahead

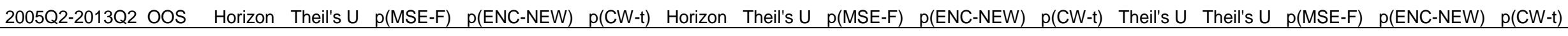

\begin{tabular}{|c|c|c|c|c|c|c|c|c|c|c|c|c|c|c|c|}
\hline Inflation-Inf & 1 & 1.0062 & 0.374 & 0.525 & 0.902 & 2 & 1.0150 & 0.446 & 0.514 & 0.616 & 4 & 1.0444 & 0.643 & 0.636 & 0.566 \\
\hline OutputGaptoGDP & 1 & 1.0279 & 0.764 & 0.822 & 0.81 & 2 & 1.0780 & 0.87 & 0.758 & 0.534 & 4 & 1.2849 & 0.961 & 0.59 & 0.464 \\
\hline M2Growth & 1 & 1.0121 & 0.548 & 0.502 & 0.442 & 2 & 1.0363 & 0.719 & 0.797 & 0.872 & 4 & 1.1182 & 0.848 & 0.923 & 0.975 \\
\hline CommodityIndexGrowth & 1 & 0.9234 & 0.001 & 0.006 & 0.015 & 2 & 0.9389 & 0.026 & 0.026 & 0.104 & 4 & 0.9943 & 0.229 & 0.223 & 0.284 \\
\hline FXchange & 1 & 1.0382 & 0.898 & 0.9 & 0.542 & 2 & 1.0877 & 0.924 & 0.822 & 0.483 & 4 & 1.3103 & 0.993 & 0.926 & 0.565 \\
\hline CAY & 1 & 1.0319 & 0.76 & 0.372 & 0.349 & 2 & 1.0758 & 0.823 & 0.671 & 0.474 & 4 & 1.1196 & 0.770 & 0.851 & 0.682 \\
\hline Wealth-Income & 1 & 1.0242 & 0.722 & 0.679 & 0.489 & 2 & 1.0635 & 0.759 & 0.793 & 0.573 & 4 & 1.0695 & 0.676 & 0.806 & 0.807 \\
\hline RiskFree-MMR/TBL & 1 & 1.0127 & 0.604 & 0.355 & 0.361 & 2 & 1.0517 & 0.863 & 0.839 & 0.606 & 4 & 1.0426 & 0.757 & 0.349 & 0.349 \\
\hline Price-GDP & 1 & 1.0079 & 0.419 & 0.437 & 0.434 & 2 & 1.0036 & 0.338 & 0.365 & 0.345 & 4 & 1.0203 & 0.406 & 0.395 & 0.38 \\
\hline CBRate & 1 & 0.9549 & 0.011 & 0.029 & 0.009 & 2 & 0.9573 & 0.044 & 0.080 & 0.047 & 4 & 0.9780 & 0.157 & 0.207 & 0.156 \\
\hline CAY_RT & 1 & 1.0299 & 0.774 & 0.559 & 0.423 & 2 & 1.0719 & 0.808 & 0.741 & 0.512 & 4 & 1.0997 & 0.736 & 0.841 & 0.719 \\
\hline Wealth-Income_RT & 1 & 1.0264 & 0.702 & 0.622 & 0.563 & 2 & 1.0366 & 0.600 & 0.684 & 0.735 & 4 & 1.0286 & 0.450 & 0.292 & 0.343 \\
\hline OutputGap to GDP RT & 1 & 1.0472 & 0.912 & 0.219 & 0.285 & 2 & 1.0572 & 0.822 & 0.661 & 0.545 & 4 & 1.0722 & 0.705 & 0.769 & 0.638 \\
\hline
\end{tabular}

Panel B: US Predictors

\begin{tabular}{|c|c|c|c|c|c|c|c|c|c|c|c|c|c|c|c|}
\hline 1995Q1-2004Q4 INS & & One qua & rter ahead & & & & Two quar & ters ahead & & & & Four qua & ters ahead & & \\
\hline 2005Q2-2013Q2 OOS & Horizon & Theil's U & $\mathrm{p}(\mathrm{MSE}-\mathrm{F})$ & $\mathrm{p}(\mathrm{ENC}-\mathrm{NEW})$ & $p(C W-t)$ & Horizon & Theil's U & $\mathrm{p}(\mathrm{MSE}-\mathrm{F})$ & $\mathrm{p}(\mathrm{ENC}-\mathrm{NEW})$ & $p(C W-t)$ & Theil's U & Theil's U & $\mathrm{p}(\mathrm{MSE}-\mathrm{F})$ & $\mathrm{p}(\mathrm{ENC}-\mathrm{NEW})$ & $p(C W-t)$ \\
\hline Inflation-Inf & 1 & 1.0089 & 0.486 & 0.547 & 0.570 & 2 & 1.0322 & 0.793 & 0.807 & 0.535 & 4 & 1.0610 & 0.845 & 0.859 & 0.777 \\
\hline OutputGaptoGDP & 1 & 0.9789 & 0.058 & 0.035 & 0.084 & 2 & 0.9782 & 0.127 & 0.055 & 0.174 & 4 & 1.0116 & 0.35 & 0.094 & 0.233 \\
\hline M2Growth & 1 & 1.0316 & 0.885 & 0.833 & 0.664 & 2 & 1.0439 & 0.849 & 0.842 & 0.826 & 4 & 1.0399 & 0.785 & 0.781 & 0.617 \\
\hline CommodityIndexGrowth & 1 & 0.9970 & 0.159 & 0.196 & 0.205 & 2 & 0.9470 & 0.018 & 0.026 & 0.151 & 4 & 0.9795 & 0.099 & 0.121 & 0.202 \\
\hline FXchange & 1 & 1.0223 & 0.826 & 0.886 & 0.804 & 2 & 1.0680 & 0.979 & 0.985 & 0.923 & 4 & 1.1118 & 0.987 & 0.999 & 0.896 \\
\hline CAY & 1 & 1.0400 & 0.874 & 0.930 & 0.974 & 2 & 1.0625 & 0.783 & 0.861 & 0.997 & 4 & 1.0798 & 0.684 & 0.377 & 0.38 \\
\hline Wealth-Income & 1 & 1.0175 & 0.639 & 0.726 & 0.643 & 2 & 1.0338 & 0.61 & 0.737 & 0.767 & 4 & 1.0985 & 0.765 & 0.882 & 0.903 \\
\hline RiskFree-MMR/TBL & 1 & 1.0449 & 0.868 & 0.916 & 0.849 & 2 & 1.0798 & 0.85 & 0.859 & 0.682 & 4 & 1.1247 & 0.763 & 0.588 & 0.487 \\
\hline Price-GDP & 1 & 0.9904 & 0.101 & 0.167 & 0.130 & 2 & 0.9853 & 0.135 & 0.219 & 0.199 & 4 & 0.9739 & 0.156 & 0.193 & 0.234 \\
\hline CBRate & 1 & 1.0395 & 0.834 & 0.779 & 0.600 & 2 & 1.0649 & 0.764 & 0.644 & 0.528 & 4 & 1.1051 & 0.698 & 0.340 & 0.372 \\
\hline CAY_RT & 1 & 1.0332 & 0.864 & 0.938 & 0.888 & 2 & 1.0641 & 0.888 & 0.946 & 0.926 & 4 & 1.1410 & 0.911 & 0.945 & 0.808 \\
\hline Wealth-Income_RT & 1 & 1.0590 & 0.922 & 0.973 & 0.959 & 2 & 1.1006 & 0.928 & 0.971 & 0.999 & 4 & 1.1370 & 0.843 & 0.768 & 0.565 \\
\hline OutputGap_to_GDP_RT & 1 & 1.0517 & 0.945 & 0.898 & 0.514 & 2 & 1.0919 & 0.912 & 0.950 & 0.672 & 4 & 1.0276 & 0.471 & 0.544 & 0.528 \\
\hline
\end{tabular}


Panel C: Global Predictors

\begin{tabular}{|c|c|c|c|c|c|c|c|c|c|c|c|c|c|c|c|}
\hline \multirow[t]{2}{*}{ 1995Q1-2013Q2 } & \multicolumn{4}{|c|}{ One quarter ahead } & \multicolumn{5}{|c|}{ Two quarters ahead } & \multicolumn{5}{|c|}{ Four quarters ahead } & \multirow[b]{2}{*}{$p(C W-t)$} \\
\hline & Horizon & Theil's U & $\mathrm{p}$ (MSE-F) & $\mathrm{p}(\mathrm{ENC}-\mathrm{NEW})$ & $p(C W-t)$ & Horizon & Theil's U & $\mathrm{p}(\mathrm{MSE}-\mathrm{F})$ & $\mathrm{p}(\mathrm{ENC}-\mathrm{NEW})$ & $\mathrm{p}(\mathrm{CW}-\mathrm{t})$ & Horizon & Theil's U & $\mathrm{p}(\mathrm{MSE}-\mathrm{F})$ & $\mathrm{p}(\mathrm{ENC}-\mathrm{NEW})$ & \\
\hline VIX & 1 & 1.0230 & 0.820 & 0.883 & 0.774 & 2 & 1.0439 & 0.820 & 0.899 & 0.759 & 4 & 1.0604 & 0.811 & 0.894 & 0.868 \\
\hline Intl Net Bank Claims & 1 & 1.0485 & 0.908 & 0.868 & 0.512 & 2 & 1.0865 & 0.910 & 0.953 & 0.851 & 4 & 1.1269 & 0.817 & 0.849 & 0.689 \\
\hline Intl Bank Claims & 1 & 1.0454 & 0.918 & 0.785 & 0.572 & 2 & 1.0602 & 0.831 & 0.752 & 0.608 & 4 & 1.0529 & 0.618 & 0.459 & 0.419 \\
\hline G7 Output Gap & 1 & 1.0253 & 0.731 & 0.061 & 0.119 & 2 & 1.0701 & 0.812 & 0.225 & 0.262 & 4 & 1.1224 & 0.799 & 0.629 & 0.608 \\
\hline G7 Output Gap RT & 1 & 1.0980 & 0.983 & 0.002 & 0.057 & 2 & 1.3065 & 0.996 & 0.030 & 0.114 & 4 & 1.5876 & 0.993 & 0.137 & 0.181 \\
\hline
\end{tabular}

Notes: Table 10 shows out-of-sample forecasting for returns at the one quarter, two quarter and four quarter horizons. Theil's $U$ is the ratio of the forecast error of the regression model to that of the

historical average benchmark. MSE-F and CW-t are tests for equal forecast accuracy. ENC NEW tests for encompassing. The one-sided p-values for these tests are based on a bootstrapping procedure described in Section 3.2. Bold type is used to denote significance at the $10 \%$ level for a one-sided test. 
Table 11: Out-of-sample forecast regressions - China.

Panel A: Domestic Predictors

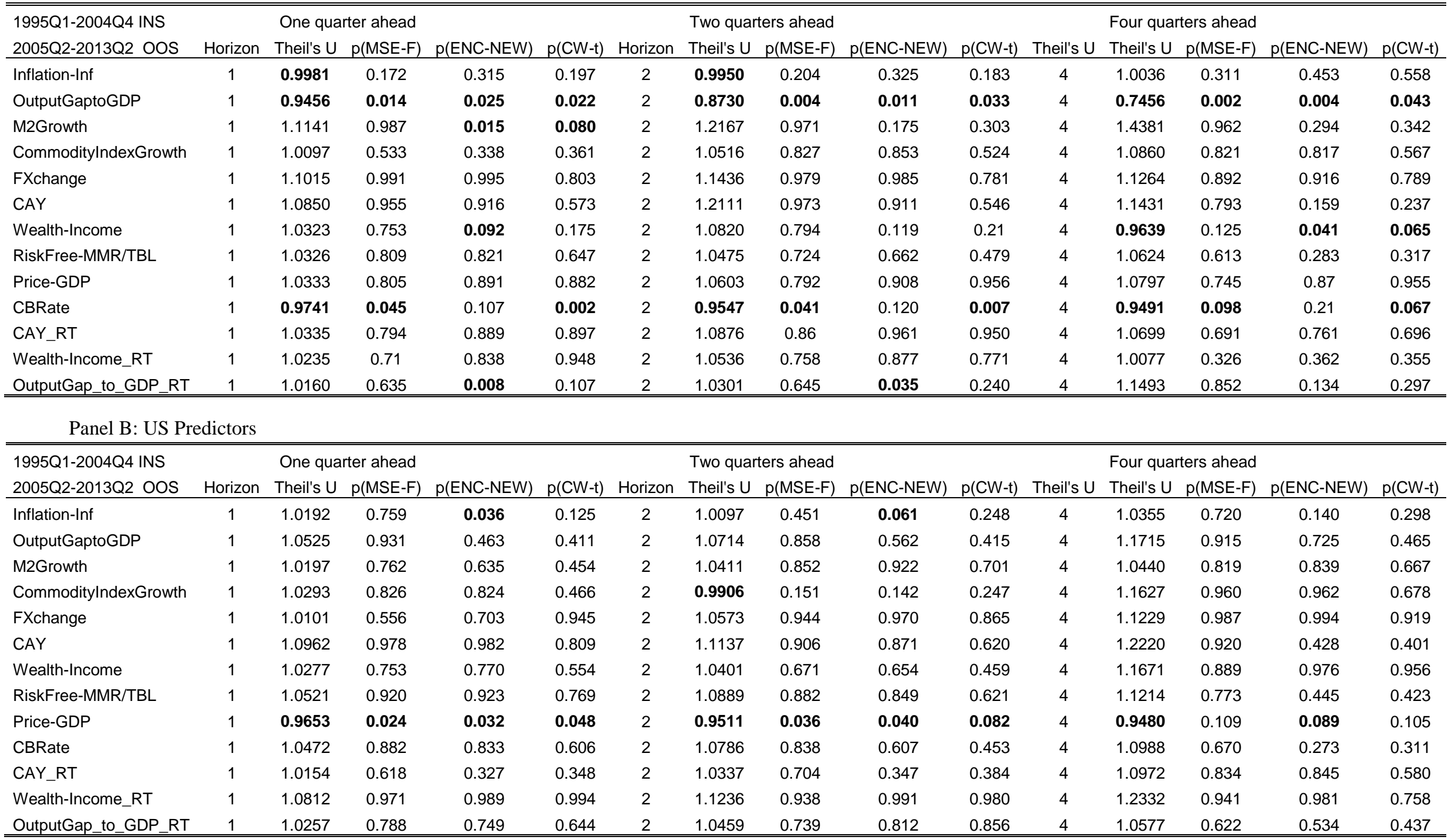


Panel C: Global Predictors

\begin{tabular}{|c|c|c|c|c|c|c|c|c|c|c|c|c|c|c|c|}
\hline \multirow[t]{2}{*}{ 1995Q1-2013Q2 } & \multicolumn{4}{|c|}{ One quarter ahead } & \multicolumn{5}{|c|}{ Two quarters ahead } & \multicolumn{5}{|c|}{ Four quarters ahead } & \multirow[b]{2}{*}{$\mathrm{p}(\mathrm{CW}-\mathrm{t})$} \\
\hline & Horizon & Theil's U & $\mathrm{p}(\mathrm{MSE}-\mathrm{F})$ & $\mathrm{p}(\mathrm{ENC}-\mathrm{NEW})$ & $\mathrm{p}(\mathrm{CW}-\mathrm{t})$ & Horizon & Theil's U & $\mathrm{p}(\mathrm{MSE}-\mathrm{F})$ & $\mathrm{p}(\mathrm{ENC}-\mathrm{NEW})$ & $\mathrm{p}(\mathrm{CW}-\mathrm{t})$ & Horizon & Theil's U & $\mathrm{p}(\mathrm{MSE}-\mathrm{F})$ & $\mathrm{p}(\mathrm{ENC}-\mathrm{NEW})$ & \\
\hline VIX & 1 & 1.0209 & 0.747 & 0.730 & 0.557 & 2 & 1.0638 & 0.887 & 0.869 & 0.528 & 4 & 1.0995 & 0.887 & 0.924 & 0.778 \\
\hline Intl Net Bank Claims & 1 & 1.0512 & 0.932 & 0.388 & 0.398 & 2 & 1.1135 & 0.945 & 0.933 & 0.634 & 4 & 1.2183 & 0.933 & 0.986 & 0.957 \\
\hline Intl Bank Claims & 1 & 1.0361 & 0.836 & 0.884 & 0.616 & 2 & 1.0838 & 0.896 & 0.959 & 0.988 & 4 & 1.1015 & 0.765 & 0.888 & 0.948 \\
\hline G7 Output Gap & 1 & 1.0508 & 0.885 & 0.829 & 0.642 & 2 & 1.0943 & 0.874 & 0.939 & 0.891 & 4 & 1.1271 & 0.809 & 0.927 & 0.918 \\
\hline G7 Output Gap RT & 1 & 1.1249 & 0.989 & 0.016 & 0.067 & 2 & 1.2710 & 0.993 & 0.059 & 0.158 & 4 & 1.4515 & 0.985 & 0.166 & 0.201 \\
\hline
\end{tabular}

Notes: Table 11 shows out-of-sample forecasting for returns at the one quarter, two quarter and four quarter horizons. Theil's $U$ is the ratio of the forecast error of the regression model to that of the historical average benchmark. MSE-F and CW-t are tests for equal forecast accuracy. ENC NEW tests for encompassing. The one-sided p-values for these tests are based on a bootstrapping procedure described in Section 3.2. Bold type is used to denote significance at the $10 \%$ level for a one-sided test. 
Table 12: Out-of-sample forecast regressions - South Africa.

Panel A: Domestic Predictors

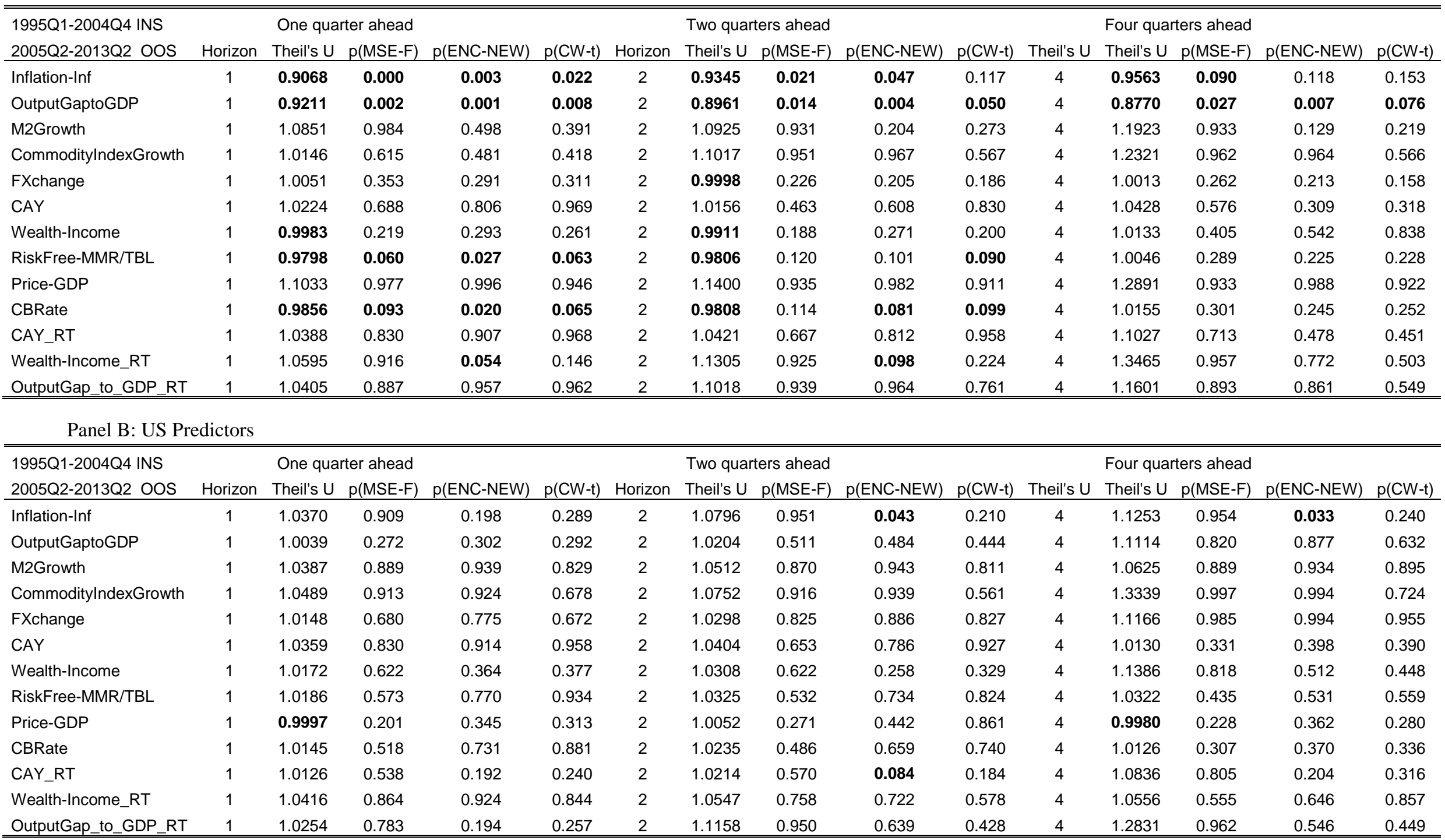


coefficientcoefficientcoefficientcoefficientPanel C: Global Predictors

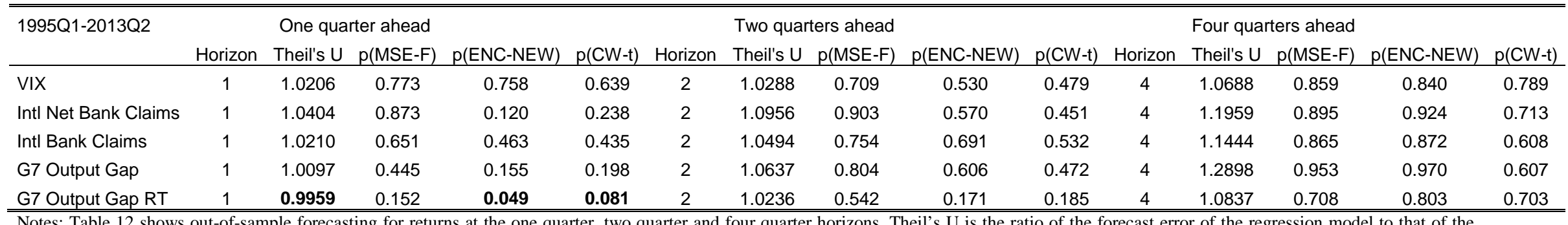

Notes: Table 12 shows out-of-sample forecasting for returns at the one quarter, two quarter and four quarter horizons. Theil's $\mathrm{U}$ is the ratio of the forecast error of the regression model to that of the historical average benchmark. MSE-F and CW-t are tests for equal forecast accuracy. ENC NEW tests for encompassing. The one-sided p-values for these tests are based on a bootstrapping procedure described in Section 3.2. Bold type is used to denote significance at the $10 \%$ level for a one-sided test.

coefficient 


\section{APPENDIX A - RESULTS WITH LAGGED DEPENDENT VARIABLE.}

Table A.1: In-sample forecast regressions including lag dependent variable for domestic predictors - Brazil.

\begin{tabular}{|c|c|c|c|c|c|c|c|c|c|c|c|c|c|c|c|}
\hline \multirow[t]{2}{*}{ 1995Q1-2013Q2 } & \multicolumn{4}{|c|}{ One quarter ahead } & \multicolumn{5}{|c|}{ Two quarters ahead } & \multicolumn{6}{|c|}{ Four quarters ahead } \\
\hline & Horizon & Slope & $\mathrm{t}$ & $\mathrm{p}(\mathrm{t})$ & R-sq & Horizon & Slope & $\mathrm{t}$ & $p(t)$ & R-sq & Horizon & Slope & $\mathrm{t}$ & $\mathrm{p}(\mathrm{t})$ & R-sq \\
\hline Inflation-Inf & 1 & 0.5193 & 1.015 & 0.1600 & 0.032 & 2 & 3.0582 & 1.582 & 0.1010 & 0.044 & 4 & 8.6789 & 2.406 & 0.0260 & 0.1971 \\
\hline OutputGaptoGDP & 1 & -0.3409 & -2.854 & 1.0000 & 0.121 & 2 & -0.7230 & -3.696 & 0.9980 & 0.219 & 4 & -0.9599 & -3.790 & 0.9960 & 0.2928 \\
\hline M2Growth & 1 & -0.5053 & -1.012 & 0.8320 & 0.032 & 2 & -1.3836 & -1.081 & 0.8070 & 0.040 & 4 & -2.1736 & -0.841 & 0.7560 & 0.1167 \\
\hline CommodityIndexGrowth & 1 & -0.1906 & -1.708 & 0.9530 & 0.057 & 2 & -0.3149 & -1.208 & 0.8130 & 0.054 & 4 & -0.1678 & -0.440 & 0.6170 & 0.0908 \\
\hline FXchange & 1 & -0.2618 & -2.046 & 0.9750 & 0.074 & 2 & -0.5081 & -2.525 & 0.9730 & 0.094 & 4 & -0.5085 & -1.560 & 0.8710 & 0.1292 \\
\hline CAY & 1 & 0.1091 & 0.797 & 0.2310 & 0.031 & 2 & 0.1644 & 0.907 & 0.2310 & 0.018 & 4 & -0.1137 & -0.417 & 0.6220 & 0.1321 \\
\hline Wealth-Income & 1 & 0.1471 & 1.137 & 0.1180 & 0.038 & 2 & 0.3925 & 1.876 & 0.0590 & 0.061 & 4 & 0.4381 & 1.189 & 0.1910 & 0.1436 \\
\hline RiskFree-MMR/TBL & 1 & 0.1726 & 1.402 & 0.0750 & 0.045 & 2 & 0.3956 & 1.312 & 0.1550 & 0.053 & 4 & 1.1692 & 2.109 & 0.0850 & 0.2249 \\
\hline Price-GDP & 1 & -0.2192 & -1.892 & 0.8610 & 0.066 & 2 & -0.4659 & -2.242 & 0.8530 & 0.096 & 4 & -0.8650 & -2.672 & 0.8310 & 0.2307 \\
\hline CBRate & 1 & 0.0698 & 0.554 & 0.2870 & 0.024 & 2 & 0.3440 & 1.823 & 0.0730 & 0.061 & 4 & 1.1767 & 5.396 & 0.0030 & 0.3898 \\
\hline
\end{tabular}

Notes: Table A.1 shows results of in-sample predictive regressions for one quarter (Horizon =1), two quarter (Horizon=2) and four quarter (Horizon=4) returns. See Table 1 for variable descriptions. Beta is the slope coefficient on the output gap, $t$ is the $t$-statistic based on Newey-West procedure, $\mathrm{p}(\mathrm{t})$ is the one-sided p-value estimated from the bootstrap procedure described in section 3.2 of the text. R-sq is the goodness of fit. Bold type is used to demonstrate significance at the $10 \%$ level; for the bootstrapped p-value this occurs when $\mathrm{p}(\mathrm{t})$ is greater than 0.95 or less than 0.05 .

Table A.2: In-sample forecast regressions including lag dependent variable for domestic predictors - Russia.

\begin{tabular}{|c|c|c|c|c|c|c|c|c|c|c|c|c|c|c|c|}
\hline \multirow[t]{2}{*}{ 1995Q1-2013Q2 } & \multicolumn{4}{|c|}{ One quarter ahead } & \multicolumn{5}{|c|}{ Two quarters ahead } & \multicolumn{6}{|c|}{ Four quarters ahead } \\
\hline & Horizon & Slope & $\mathrm{t}$ & $\mathrm{p}(\mathrm{t})$ & $\mathrm{R}-\mathrm{sq}$ & Horizon & Slope & $\mathrm{t}$ & $\mathrm{p}(\mathrm{t})$ & R-sq & Horizon & Slope & $\mathrm{t}$ & $\mathrm{p}(\mathrm{t})$ & R-sq \\
\hline Inflation-Inf & 1 & 0.0838 & 0.631 & 0.2820 & 0.014 & 2 & 0.5229 & 2.096 & 0.0610 & 0.080 & 4 & 1.3710 & 2.732 & 0.0360 & 0.2560 \\
\hline OutputGaptoGDP & 1 & -0.3311 & -2.909 & 0.9960 & 0.116 & 2 & -0.6881 & -4.435 & 1.0000 & 0.217 & 4 & -1.0023 & -3.700 & 0.9860 & 0.3594 \\
\hline M2Growth & 1 & 0.0500 & 0.395 & 0.2380 & 0.016 & 2 & 0.0346 & 0.221 & 0.3480 & 0.094 & 4 & 0.2422 & 1.461 & 0.1280 & 0.1205 \\
\hline CommodityIndexGrowth & 1 & -0.1289 & -1.101 & 0.8520 & 0.025 & 2 & -0.2159 & -0.770 & 0.7250 & 0.028 & 4 & 0.0369 & 0.072 & 0.4480 & 0.1458 \\
\hline FXchange & 1 & -0.2256 & -1.897 & 0.9650 & 0.057 & 2 & -0.5346 & -3.444 & 0.9980 & 0.124 & 4 & -0.5227 & -3.177 & 0.9700 & 0.1996 \\
\hline CAY & 1 & -0.0201 & -0.151 & 0.5760 & 0.009 & 2 & 0.0741 & 0.204 & 0.4510 & 0.009 & 4 & -0.1157 & -0.221 & 0.5580 & 0.1517 \\
\hline Wealth-Income & 1 & 0.0250 & 0.177 & 0.4360 & 0.009 & 2 & -0.2760 & -1.349 & 0.8590 & 0.028 & 4 & -1.1034 & -1.601 & 0.8530 & 0.2220 \\
\hline RiskFree-MMR/TBL & 1 & 0.0331 & 0.133 & 0.4510 & 0.008 & 2 & 0.3509 & 0.917 & 0.2470 & 0.017 & 4 & 1.1436 & 0.705 & 0.3090 & 0.1683 \\
\hline Price-GDP & 1 & 0.0985 & 0.788 & 0.1850 & 0.018 & 2 & 0.1269 & 0.425 & 0.3520 & 0.010 & 4 & 0.1264 & 0.305 & 0.3680 & 0.1914 \\
\hline CBRate & 1 & 0.0058 & 0.044 & 0.4740 & 0.008 & 2 & 0.3794 & 2.210 & 0.0630 & 0.049 & 4 & 1.1233 & 2.644 & 0.0580 & 0.2452 \\
\hline
\end{tabular}

Notes: Table A.2 shows results of in-sample predictive regressions for one quarter (Horizon =1), two quarter (Horizon=2) and four quarter (Horizon=4) returns. See Table 1 for variable descriptions. Beta is the slope coefficient on the output gap, $t$ is the $t$-statistic based on Newey-West procedure, $\mathrm{p}(\mathrm{t})$ is the one-sided p-value estimated from the bootstrap procedure described in section 3.2 of the text. $\mathrm{R}$-sq is the goodness of fit. Bold type is used to demonstrate significance at the $10 \%$ level; for the bootstrapped p-value this occurs when $\mathrm{p}(\mathrm{t})$ is greater than 0.95 or less than 0.05 . 
Table A.3: In-sample forecast regressions including lag dependent variable for domestic predictors - India.

\begin{tabular}{|c|c|c|c|c|c|c|c|c|c|c|c|c|c|c|c|}
\hline \multirow[t]{2}{*}{ 1995Q1-2013Q2 } & \multicolumn{4}{|c|}{ One quarter ahead } & \multicolumn{5}{|c|}{ Two quarters ahead } & \multicolumn{6}{|c|}{ Four quarters ahead } \\
\hline & Horizon & Slope & $\mathrm{t}$ & $\mathrm{p}(\mathrm{t})$ & R-sq & Horizon & Slope & $\mathrm{t}$ & $\mathrm{p}(\mathrm{t})$ & $\mathrm{R}$-sq & Horizon & Slope & $\mathrm{t}$ & $\mathrm{p}(\mathrm{t})$ & R-sq \\
\hline Inflation-Inf & 1 & 0.0562 & 0.473 & 0.3490 & 0.030 & 2 & 0.1455 & 0.784 & 0.2840 & 0.011 & 4 & 0.2835 & 0.680 & 0.3770 & 0.0934 \\
\hline OutputGaptoGDP & 1 & 0.0066 & 0.048 & 0.4520 & 0.038 & 2 & -0.1031 & -0.427 & 0.5890 & 0.004 & 4 & -0.2504 & -0.475 & 0.5970 & 0.0855 \\
\hline M2Growth & 1 & -0.0388 & -0.294 & 0.6180 & 0.048 & 2 & -0.0576 & -0.189 & 0.5580 & 0.001 & 4 & -0.3437 & -0.742 & 0.6930 & 0.0803 \\
\hline CommodityIndexGrowth & 1 & -0.2830 & -2.479 & 0.9840 & 0.107 & 2 & -0.5277 & -1.871 & 0.9320 & 0.123 & 4 & -0.4087 & -1.239 & 0.8120 & 0.1089 \\
\hline FXchange & 1 & -0.0933 & -0.795 & 0.8030 & 0.036 & 2 & -0.2635 & -1.072 & 0.8040 & 0.032 & 4 & -0.4119 & -1.191 & 0.7980 & 0.1133 \\
\hline CAY & 1 & -0.0491 & -0.368 & 0.6490 & 0.048 & 2 & -0.1156 & -0.410 & 0.6440 & 0.006 & 4 & 0.0652 & 0.147 & 0.4660 & 0.0834 \\
\hline Wealth-Income & 1 & -0.0196 & -0.148 & 0.5540 & 0.046 & 2 & -0.0142 & -0.050 & 0.4780 & 0.001 & 4 & -0.2799 & -0.755 & 0.7060 & 0.0975 \\
\hline RiskFree-MMR/TBL & 1 & -0.0554 & -0.458 & 0.7220 & 0.030 & 2 & -0.0368 & -0.186 & 0.5730 & 0.003 & 4 & -0.3832 & -1.203 & 0.8060 & 0.1030 \\
\hline Price-GDP & 1 & -0.1943 & -1.569 & 0.7550 & 0.071 & 2 & -0.3661 & -1.447 & 0.6000 & 0.052 & 4 & -0.5860 & -1.534 & 0.5130 & 0.1413 \\
\hline CBRate & 1 & -0.2055 & -1.704 & 0.9570 & 0.066 & 2 & -0.4666 & -1.976 & 0.9370 & 0.081 & 4 & -0.9292 & -2.477 & 0.9290 & 0.2073 \\
\hline
\end{tabular}

Notes: Table A.3 shows results of in-sample predictive regressions for one quarter (Horizon =1), two quarter (Horizon=2) and four quarter (Horizon=4) returns. See Table 1 for variable descriptions. Beta is the slope coefficient on the output gap, $t$ is the $t$-statistic based on Newey-West procedure, $p(t)$ is the one-sided p-value estimated from the bootstrap procedure described in section 3.2 of the text. $\mathrm{R}$-sq is the goodness of fit. Bold type is used to demonstrate significance at the $10 \%$ level; for the bootstrapped p-value this occurs when $\mathrm{p}(\mathrm{t})$ is greater than 0.95 or less than 0.05 .

Table A.4: In-sample forecast regressions including lag dependent variable for domestic predictors - China.

\begin{tabular}{|c|c|c|c|c|c|c|c|c|c|c|c|c|c|c|c|}
\hline \multirow[t]{2}{*}{ 1995Q1-2013Q2 } & \multicolumn{4}{|c|}{ One quarter ahead } & \multicolumn{5}{|c|}{ Two quarters ahead } & \multicolumn{6}{|c|}{ Four quarters ahead } \\
\hline & Horizon & Slope & $\mathrm{t}$ & $p(t)$ & $\mathrm{R}-\mathrm{sq}$ & Horizon & Slope & $\mathrm{t}$ & $p(t)$ & R-sq & Horizon & Slope & $\mathrm{t}$ & $p(t)$ & R-sq \\
\hline Inflation-Inf & 1 & -0.1142 & -0.816 & 0.7800 & 0.010 & 2 & -0.1223 & -0.471 & 0.6380 & 0.013 & 4 & -0.2031 & -0.362 & 0.5700 & 0.0224 \\
\hline OutputGaptoGDP & 1 & -0.2492 & -1.854 & 0.9680 & 0.052 & 2 & -0.5247 & -2.936 & 0.9910 & 0.123 & 4 & -1.3450 & -5.332 & 0.9960 & 0.3576 \\
\hline M2Growth & 1 & 0.1922 & 1.442 & 0.0450 & 0.035 & 2 & 0.2751 & 1.519 & 0.0870 & 0.035 & 4 & 0.3900 & 1.548 & 0.1420 & 0.0384 \\
\hline CommodityIndexGrowth & 1 & -0.1267 & -1.052 & 0.8590 & 0.016 & 2 & -0.1665 & -0.715 & 0.7180 & 0.023 & 4 & 0.1650 & 0.406 & 0.4400 & 0.0245 \\
\hline FXchange & 1 & -0.1037 & -0.842 & 0.8440 & 0.010 & 2 & -0.1473 & -0.531 & 0.6790 & 0.018 & 4 & -0.5205 & -0.995 & 0.7590 & 0.0645 \\
\hline CAY & 1 & 0.0397 & 0.283 & 0.3860 & 0.002 & 2 & 0.1342 & 0.430 & 0.3590 & 0.019 & 4 & 1.0937 & 1.979 & 0.1120 & 0.1410 \\
\hline Wealth-Income & 1 & -0.1356 & -0.988 & 0.8350 & 0.016 & 2 & -0.3195 & -1.153 & 0.8140 & 0.049 & 4 & -1.5074 & -2.974 & 0.9440 & 0.2847 \\
\hline RiskFree-MMR/TBL & 1 & -0.1007 & -0.820 & 0.8040 & 0.010 & 2 & -0.1795 & -0.940 & 0.7760 & 0.023 & 4 & -0.7096 & -1.899 & 0.9000 & 0.1172 \\
\hline Price-GDP & 1 & -0.1075 & -0.834 & 0.7060 & 0.011 & 2 & -0.2109 & -0.801 & 0.6600 & 0.029 & 4 & -0.1342 & -0.274 & 0.5050 & 0.0190 \\
\hline CBRate & 1 & -0.1630 & -1.315 & 0.8650 & 0.025 & 2 & -0.2806 & -1.119 & 0.7550 & 0.043 & 4 & -0.8530 & -1.510 & 0.8090 & 0.1276 \\
\hline
\end{tabular}

Notes: Table A.4 shows results of in-sample predictive regressions for one quarter (Horizon =1), two quarter (Horizon=2) and four quarter (Horizon=4) returns. See Table 1 for variable descriptions. Beta is the slope coefficient on the output gap, $t$ is the $t$-statistic based on Newey-West procedure, $\mathrm{p}(\mathrm{t})$ is the one-sided $\mathrm{p}$-value estimated from the bootstrap procedure described in section 3.2 of the text. $\mathrm{R}$-sq is the goodness of fit. Bold type is used to demonstrate significance at the $10 \%$ level; for the bootstrapped p-value this occurs when $\mathrm{p}(\mathrm{t})$ is greater than 0.95 or less than 0.05 . 
Table A.5: In-sample forecast regressions including lag dependent variable for domestic predictors - South Africa.

\begin{tabular}{|c|c|c|c|c|c|c|c|c|c|c|c|c|c|c|c|}
\hline \multirow[t]{2}{*}{ 1995Q1-2013Q2 } & \multicolumn{4}{|c|}{ One quarter ahead } & \multicolumn{5}{|c|}{ Two quarters ahead } & \multicolumn{6}{|c|}{ Four quarters ahead } \\
\hline & Horizon & Slope & $\mathrm{t}$ & $p(t)$ & R-sq & Horizon & Slope & $\mathrm{t}$ & $\mathrm{p}(\mathrm{t})$ & R-sq & Horizon & Slope & $\mathrm{t}$ & $\mathrm{p}(\mathrm{t})$ & R-sq \\
\hline Inflation-Inf & 1 & -0.2938 & -2.378 & 0.9960 & 0.078 & 2 & -0.6046 & -2.923 & 0.9810 & 0.146 & 4 & -1.1215 & -4.932 & 0.9990 & 0.2487 \\
\hline OutputGaptoGDP & 1 & -0.3094 & -2.678 & 0.9950 & 0.096 & 2 & -0.5918 & -4.345 & 1.0000 & 0.193 & 4 & -0.9678 & -4.277 & 0.9900 & 0.3042 \\
\hline M2Growth & 1 & -0.1357 & -1.148 & 0.8400 & 0.021 & 2 & -0.2788 & -1.852 & 0.9180 & 0.051 & 4 & -0.5593 & -1.887 & 0.8800 & 0.1053 \\
\hline CommodityIndexGrowth & 1 & -0.0841 & -0.706 & 0.7570 & 0.009 & 2 & -0.0645 & -0.264 & 0.5940 & 0.012 & 4 & 0.2083 & 0.444 & 0.3720 & 0.0308 \\
\hline FXchange & 1 & 0.0920 & 0.771 & 0.2280 & 0.011 & 2 & 0.2219 & 1.532 & 0.0960 & 0.036 & 4 & 0.4109 & 1.492 & 0.1670 & 0.0703 \\
\hline CAY & 1 & -0.0121 & -0.092 & 0.5250 & 0.002 & 2 & 0.0041 & 0.022 & 0.4910 & 0.008 & 4 & 0.2885 & 0.960 & 0.2660 & 0.0381 \\
\hline Wealth-Income & 1 & 0.0707 & 0.544 & 0.2880 & 0.007 & 2 & 0.1965 & 0.927 & 0.2470 & 0.027 & 4 & -0.0351 & -0.082 & 0.5280 & 0.0184 \\
\hline RiskFree-MMR/TBL & 1 & -0.2016 & -1.625 & 0.9800 & 0.039 & 2 & -0.3932 & -1.888 & 0.9660 & 0.075 & 4 & -0.7867 & -2.272 & 0.9680 & 0.1472 \\
\hline Price-GDP & 1 & -0.0624 & -0.507 & 0.4890 & 0.006 & 2 & -0.0495 & -0.244 & 0.3510 & 0.011 & 4 & 0.0078 & 0.019 & 0.3090 & 0.0200 \\
\hline CBRate & 1 & -0.2216 & -1.798 & 0.9860 & 0.047 & 2 & -0.3998 & -1.818 & 0.9660 & 0.079 & 4 & -0.7671 & -2.127 & 0.9490 & 0.1419 \\
\hline
\end{tabular}

Notes: Table A.5 shows results of in-sample predictive regressions for one quarter (Horizon =1), two quarter (Horizon=2) and four quarter (Horizon=4) returns. See Table 1 for variable descriptions. Beta is the slope coefficient on the output gap, $t$ is the t-statistic based on Newey-West procedure, $\mathrm{p}(\mathrm{t})$ is the one-sided p-value estimated from the bootstrap procedure described in section 3.2 of the text. $\mathrm{R}$-sq is the goodness of fit. Bold type is used to demonstrate significance at the $10 \%$ level; for the bootstrapped p-value this occurs when $\mathrm{p}(\mathrm{t})$ is greater than 0.95 or less than 0.05 . 